Christopher Koch, Lion Hirth

\title{
Short-term electricity trading for system balancing: An empirical analysis of the role of intraday trading in balancing Germany's electricity system
}

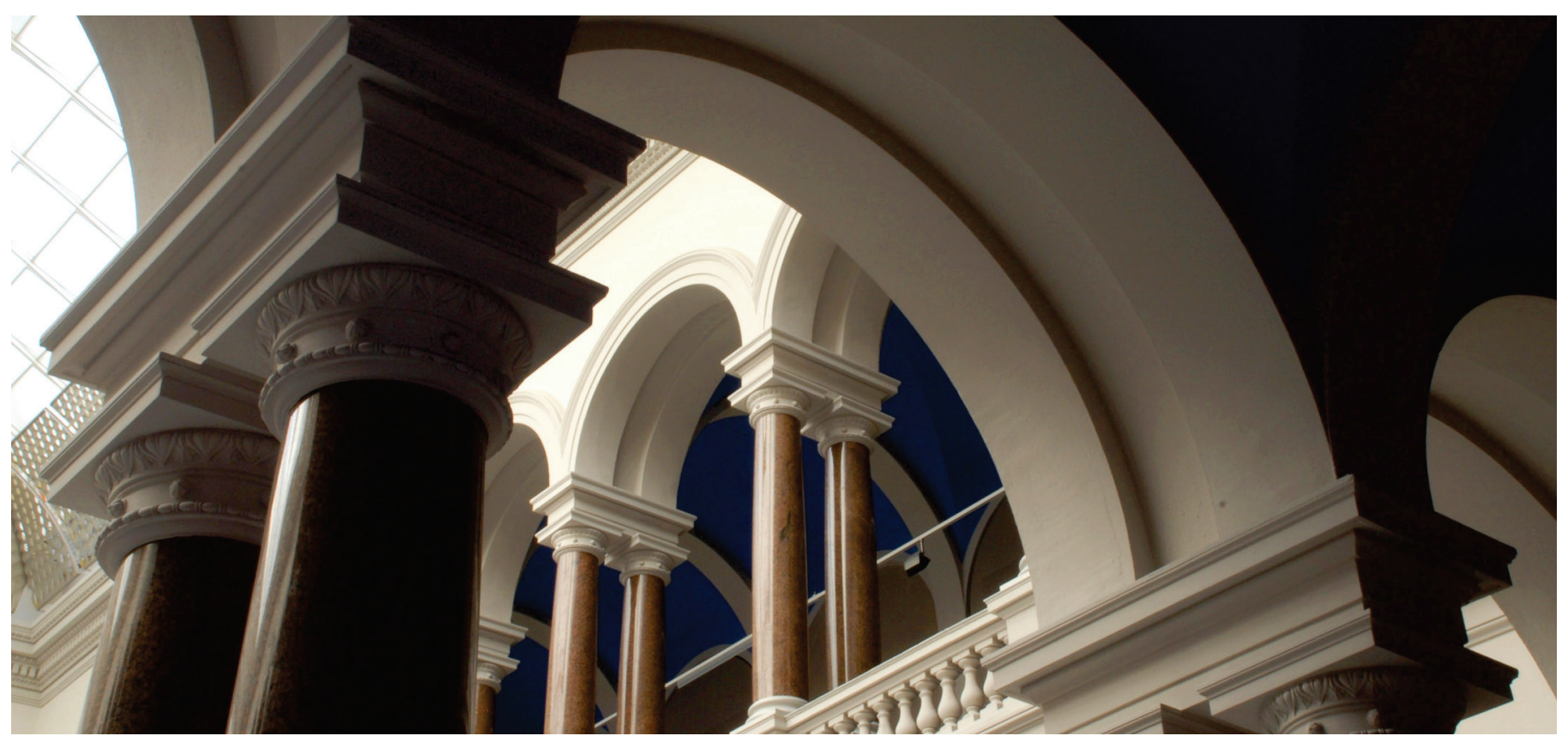

Koch, C., \& Hirth, L. (2019). Short-term electricity trading for system balancing: An empirical analysis of the role of intraday trading in balancing Germany's electricity system. Renewable and Sustainable Energy Reviews, 113, 109275. https://doi.org/10.1016/j.rser.2019.109275 


\title{
Short-Term Electricity Trading for System Balancing
}

\section{An Empirical Analysis of the Role of Intraday Trading in Balancing Germany's Electricity System}

\author{
Christopher Koch ${ }^{\mathrm{a}, *}$ and Lion Hirth ${ }^{\mathrm{b}, \mathrm{c}, \mathrm{d}}$ \\ a Department of Energy Systems, Berlin University of Technology, Einsteinufer 25, 10587 Berlin, Germany \\ ${ }^{b}$ Neon Neue Energieökonomik GmbH (Neon), Germany \\ c Hertie School of Governance, Germany \\ ${ }^{a}$ Mercator Research Institute on Global Commons and Climate Change (MCC), Germany
}

\begin{abstract}
Previous studies have noted that, unexpectedly, Germany's dramatic expansion of wind and solar energy coincided with a reduction of short-term balancing reserves. This observation has been dubbed the "German Balancing Paradox". This paper provides further and updated evidence: since 2011, wind and solar energy have nearly doubled while both reserve requirements and reserve use have declined by $50 \%$. The paper quantitatively explores one reason for reduced balancing needs: increased and improved short-term wholesale electricity trading on the intraday market. Trading is now commonly done around the clock and based on quarter-hour, rather than full-hour, contracts. The shift to quarter-hourly products alone explains a decrease in balancing energy by $17 \%$. There is also strong evidence that market parties respond efficiently to imbalance charges, suggesting that incentive-based approaches to electricity balancing work.
\end{abstract}

Highlights

- $\quad$ Since 2011 wind and solar energy nearly doubled; balancing energy decreased by $50 \%$.

- One reason for this is the expansion of short-term electricity trading.

- It is now common to trade electricity around the clock, and on a 15-min basis.

- In general, the paper finds support for efficient short-term electricity markets.

- Good market design allows integrating large volumes of renewable energy at low cost.

Keywords: balancing energy; intraday market; variable renewables; wind energy, solar energy; market design; renewables system integration

*corresponding author, christopher.koch@tu-berlin.de

Address: Department of Energy Systems, Berlin University of Technology, Einsteinufer 25, 10587 Berlin, Germany

This is the Accepted Manuscript of: Koch, C., \& Hirth, L. (2019). Short-term electricity trading for system balancing: An empirical analysis of the role of intraday trading in balancing Germany's electricity system. Renewable and Sustainable Energy Reviews, 113, 109275. https://doi.org/10.1016/j.rser.2019.109275

This work is licensed under a Creative Commons Attribution-NonCommercial-NoDerivatives 4.0 International License, http://creativecommons.org/licenses/by-nc-nd/4.0/. 
1 Introduction

2 Background

2.1 The Balancing System

2.2 Recent Developments in Balancing

3 Data and Market Development

3.1 Quarter-Hourly Trading

3.2 24/7 Trading

$4 \quad$ Methodology

5 Results

5.1 Quarter-Hourly Trading

5.2 24/7 Trading

5.3 Biased Balancing Incentives

6 Conclusions

Acknowledgements

References

Appendix 


\section{List of Abbreviations}

\begin{tabular}{|c|c|}
\hline aFRR & Automatic Frequency Restoration Reserve \\
\hline BRP & Balancing responsible party \\
\hline$d$ & Day of the year $(1, \ldots, 365)$ \\
\hline Dev & Within-hour deviation \\
\hline ECMWF & European Centre for Medium-Range Weather Forecasts \\
\hline ENTSO-E & European Network of Transmission System Operators for Electricity \\
\hline FCR & Frequency Containment Reserve \\
\hline FRR & Frequency Restoration Reserve \\
\hline $\mathrm{h}$ & Hour of the year $(1, \ldots, 8760)$ \\
\hline HSB & Hourly system balance \\
\hline ISP & Imbalance settlement period \\
\hline $\mathrm{mFRR}$ & Manual Frequency Restoration Reserve \\
\hline qd & Quarter-hours of each day $(1, \ldots, 96)$ \\
\hline Qd & Dummy for quarter-hours of each day $(1, \ldots, 96)$ \\
\hline qh & Quarter-hours of each hour $(1, \ldots, 4)$ \\
\hline QSB & Quarter-hourly system balance \\
\hline SB & System balance \\
\hline $\mathrm{t}$ & Quarter-hour of analysis period $(1, \ldots, 210,432)$ \\
\hline TSO & Transmission system operator \\
\hline UCTE & Union for the Co-ordination of Transmission of Electricity \\
\hline
\end{tabular}




\section{Introduction}

Wind and solar energy now supply more than $10 \%$ of the annual energy consumption in 14 of the 33 member countries of the International Energy Agency [1]. Being dependent on weather, the errors in forecasting output of these technologies cause short-term imbalances in power systems. In European electricity markets, unforeseen changes in output are handled through the intraday market where market parties trade bilaterally, or through the balancing system, where system operators activate reserves. This paper discusses the interplay between intraday markets and balancing systems in the context of the rapidly evolving contribution of wind and solar energy.

Until 5 years ago, it was conventional wisdom that expanding renewable energy drives up the need to hold standing and spinning short-term reserves. The intuition is convincing: holding everything else fixed, higher wind and solar capacity translates into larger forecast errors, increasing the reserve requirement. While disagreeing on the size, the mode-based literature is unambiguous regarding the sign of the effect [2-8].

The empirical work of Hirth and Ziegenhagen [9], however, has challenged this conventional wisdom. Specifically, they showed that the assumption of "holding everything else fixed" is quite different from the reality of an electricity system that undergoes rapid changes. They showed empirically that Germany's renewable energy expansion has been accompanied by a significant reduction in balancing reserves, an observation dubbed the "German Balancing Paradox". Of course, it is not claimed that larger wind and solar capacity caused reserves to decline. Rather, changes to processes, technology, market design and incentives - some of them possibly driven by the renewables - led to a transformation of the energy system, while others - likely exogenous - have caused a decline in balancing reserves despite the boom in renewables.

Hirth and Ziegenhagen [9] remain tentative about the reasons for reduced balancing requirements. Among the most plausible hypotheses are advanced weather forecasting techniques [10-12], closer cooperation among system operators and expanded intraday trading. Ocker and Ehrhart [13] discuss cooperation among system operators. The present study turns to trading. Intraday electricity markets have become more liquid, especially during nighttime and weekends. Also, 15-min trading was introduced in addition to 60 -min products and has been increasingly used. This enables generators to balance short-term deviations from schedules through trading, reducing the pressure on balancing systems. Hence, the contribution of this paper is to show that the "German Balancing Paradox" is not so paradoxical in the end. To this end, it addresses the following research questions:

1) What is the effect of quarter-hourly intraday trading on the system balance?

2) What is the impact of $24 / 7$ trading on the system balance?

3) Do market participants respond to balancing incentives?

There is further evidence of reduced pressure on German balancing systems, despite a continued expansion of renewable energy: during the years 2011-17, Germany's wind and solar generation more than doubled. At the same time, balancing reserves were reduced by 
$20 \%$ (they might even have been reduced by $50 \%$ according to the analysis presented here), and the use of these reserves was reduced by $55 \%$. Fifteen-minute trading helped significantly to reduce imbalances, in particular predictable imbalances stemming from the diurnal pattern in solar generation and electricity consumption. These "deterministic imbalances" were reduced by $80 \%$. To understand the relevance, consider the following thought experiment: if those improvements had not been realized between 2012 and 2017, the balancing reserve would have been $7 \%$ larger and activation volumes would have been $17 \%$ larger. There is also empirical evidence that 24/7 trading helped reduce imbalances: in the past, imbalances in non-office hours were both more frequent and more persistent - but this is no longer the case.

This research relates to the empirical literature on intraday markets for electricity. A handful of papers discuss intraday markets in the Nordic region [14], Italy [15], the Iberian Peninsula [16] and Germany [17]. This paper also relates to studies that assess the impact of factors such as renewable energy generation and forecast errors on intraday market prices $[15,16,18-22]$ or balancing markets $[23,24]$. The study most similar to ours is probably that of Remppis et al. [25], who assess the impact of 15-min trading on balancing energy needs. The present paper is broader in scope (also discussing the impact of trading around the clock), uses an expanded dataset, and applies more rigorous methods (multiple regressions as opposed to simple regressions).

\section{Background}

This section provides some context to the analysis, first by introducing the institutional setup of the balancing system and then by providing an overview of key recent market developments.

\subsection{THE BALANCING SYSTEM}

In AC electric grids, it is the active power balance that determines the utility frequency. If uptake exceeds infeed, i.e. the system is physically short of energy, the frequency drops. Deviations from nominal frequency, if large enough, can cause disconnections, damage equipment and lead to rolling blackouts. A number of regulations, processes and markets have been developed to prevent this, which can be collectively described as the "balancing system".

Historically, most of the rules governing the European balancing system stem from the UCTE Operations Handbook [26], a guidebook compiled by European TSOs, as well as national regulations issued by regulatory authorities [27]. During 2016-17, a series of network codes were implemented that provide a common legal framework for the European balancing system. Also referred to as "Network Guidelines", these documents are legally binding, as they 
are Regulations, a type of European legislation that is immediately binding and enforceable in all member states. Two Guidelines are of particular importance for the balancing system: the Electricity Balancing Guideline [28] and the Electricity Transmission System Operation Guideline [29].

In Europe, balancing systems are embedded in an electricity market design based on selfdispatch and balancing responsibility. Market parties (generators, consumers, retail suppliers and traders) determine the dispatch of their assets - hence, "self-dispatch" - and trade freely with each other. Trading may be facilitated by one of several competing power exchanges or by a broker platform, or may be bilateral.

Each electricity market actor is a "balancing responsible party" (BRP) or "program responsible party". Each physical connection point of the grid is associated with one BRP; in Germany, there exist a few thousand BRPs. They are responsible for balancing a portfolio of generators and/or loads through dispatch of physical assets or through trade. Non-metered consumers are assigned to their connecting distribution grid. BRPs provide schedules to the associated system operator and are financially accountable for deviations from these schedules. Physical consumption/generation quantities are called "(final) positions" and deviations between positions and schedules are called "imbalances". The time steps of schedules are called "imbalance settlement periods" (ISPs); they are currently 15, 30 or $60 \mathrm{~min}$ in different European countries. By the year 2020, all countries are supposed to use 15-min ISPs.

As time unfolds, BRPs may actively reduce deviations between submitted schedules and expected physical generation/consumption by either trade or dispatching own assets. Collectively, these activities are called "portfolio management". Portfolio management may include the deliberate choice not to close imbalances, i.e. to take an open position in the balancing market.

Spot markets comprise the day-ahead auction, usually taking place at noon for the individual hours of the next day, and intraday markets. Depending on the country, intraday markets are organized as a series of auctions, as continuous trading, or as a mix of the two. In some countries, quarter-hourly and half-hourly products are traded in addition to hourly products.

Germany's leading spot power exchange, EPEX SPOT, runs an opening auction for quarterhourly intraday products each day at $3 \mathrm{pm}$ for delivery the next day, followed by continuous trading. Continuous trading closes 30 min before real time; this time span is called "gate closure". This is followed by "extended trading" until 5 min before real time, but trade is restricted within the four balancing areas [30]. The volume-weighted average price of the trades between $3 \mathrm{~h}$ and 30 min before real time is called the $\mathrm{ID}_{3}$ price. This will be the reference price of the presented analyses.

The sum of BRP's balances is the system balance. TSOs are responsible for a stable network frequency and therefore have to keep the system balance close to zero. To this end, TSOs hold balancing reserves (balancing capacity) that can respond quickly. Due to unbundling regulations, system operators cannot own assets, but instead procure balancing reserves from generators and consumers. In real time, system operators activate reserves upward and downward, thereby obtaining balancing energy. 
European system operators hold a variety of reserves, mainly differentiated by the time they take to activate. Historically, they used to be called primary control, secondary control and tertiary control (also minute reserve), each of which may raise or lower the power balance (upward or downward reserve). The electricity guidelines introduced new terminology:

- Frequency Containment Reserve (FCR);

- Automatic Frequency Restoration Reserve (aFRR);

- Manual Frequency Restoration Reserve (mFRR).

The FCR is sized in a deterministic approach to match the largest credible contingency ( $\mathrm{N}-1$ criterion). It is set at $3000 \mathrm{MW}$ for the interconnected system of continental Europe ("UCTE region") and distributed to system operators pro rata relative to annual electricity consumption. The sizing of aFRR and mFRR is done by system operators using a range of methodologies, resulting in very different levels of reserves among European countries. Typically, FCR and aFRR are spinning reserves while mFRR may be standing. Batteries provide an increasing share of FCR [31].

Procurement of balancing reserves is done by various mechanisms, including legal supply obligations, bilateral negotiations, or more formalized balancing markets for periods ranging from days to years [32]. German balancing reserves are procured through Regelleistung.net, an online platform now used by various European TSOs. The design of balancing market auctions is prescribed by the regulator. In the past few years, the duration of contracts was shortened from months to weeks and days, and minimum bid sizes were reduced, leading to a strong increase in participation and competition. Both capacity and energy are remunerated on a pay-as-bid basis, and the award criterion was changed in 2018 to also include the energy price. Marginal pricing and free bids are scheduled to be introduced in 2020.

BRP imbalances - the difference between final schedules and physical positions - are settled financially by TSOs. The settlement price is called the "imbalance price" (or imbalance charge) and is calculated for each ISP. The way the imbalance price is calculated varies greatly among European countries [32].

Close to real time, market parties regularly face the choice to either close open positions through intraday trading or leave them for imbalance settlement. Some countries, including Germany, impose a legal obligation to close all open positions on intraday markets, but the inherent uncertainty in wind and solar generation means this is rarely enforced in practice. The economic incentive for BRPs to reduce imbalances is the difference between the imbalance price and the intraday price they would have paid. This spread is called "imbalance price spread" and represents the opportunity cost for imbalances. To be precise, the imbalance price spread is defined as imbalance price minus $I_{3}$ price, and it is calculated ex post for every 15-min interval. Note that at gate closure the imbalance price is not yet known.

\subsection{ReCENT DeVELOPMENTS in BaLANCING}

In 2011, Germany's combined installed generation capacity of wind and solar power was 54 GW. By 2017, it had grown to $99 \mathrm{GW}$, a 120\% increase. In annual energy terms, the growth 
was $110 \%$ [33]. It is understandable that most studies predicted a significant increase in balancing needs, even when accounting for improvements in weather forecasting (see the literature reviewed in section 1).

However, German TSOs procure less balancing reserve than they used to. During 2011-14, the total frequency restoration reserve (FRR) was $8.8 \mathrm{GW}$ on average. This includes aFRR plus mFRR for both upward and downward reserve. By the end of 2017, it had declined to 7.2 GW, corresponding to a drop of 20\% (Fig. 1). Considering the period from 2008 to 2017, wind and solar generation increased by $220 \%$ and the procured capacity dropped by $33 \%$ (see Appendix, Fig. A1).

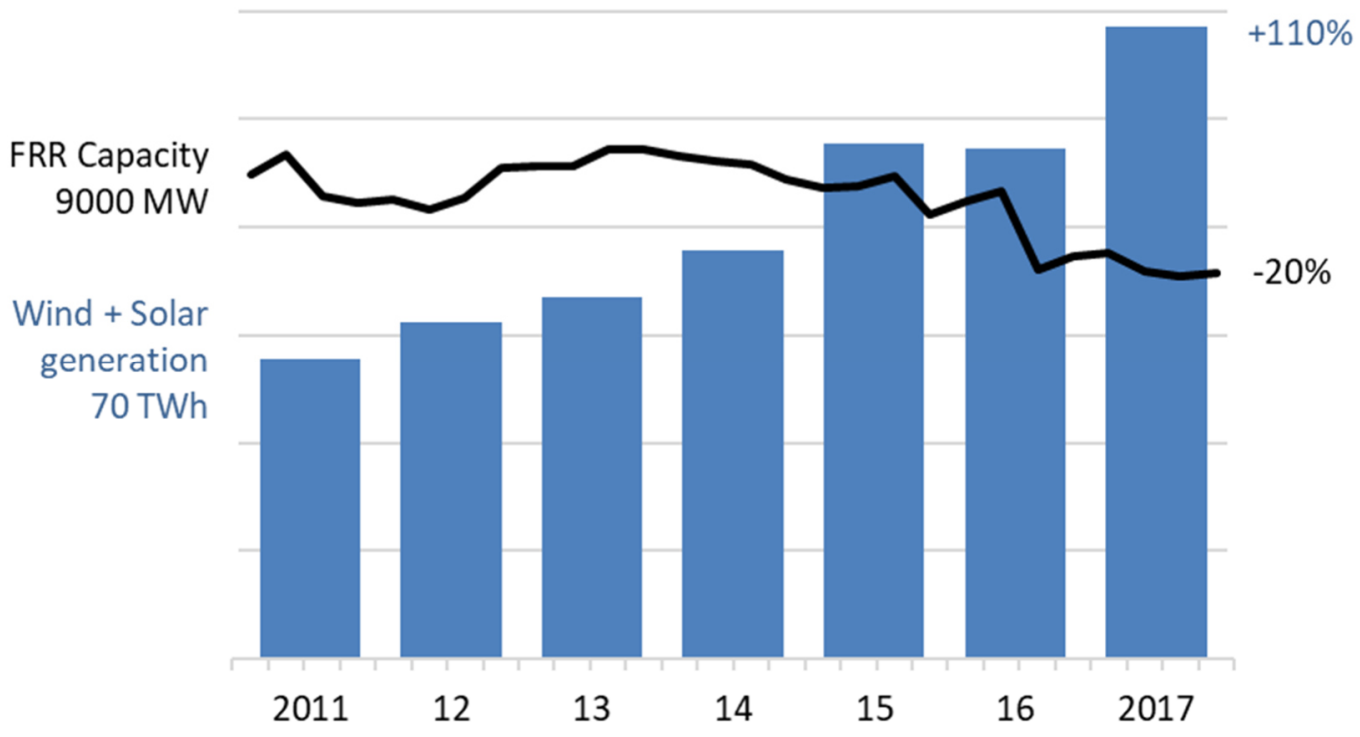

Fig. 1. Frequency restoration reserves procured by TSOs (balancing reserve) and generated energy from wind and solar plants. The period ends in 2017 because in 2018 the German regulator introduced a new approach for balancing reserve procurement showing a high potential to influence the behavior of market participants [34].

The amount of balancing energy (i.e. the activation of reserves) has declined even more: it dropped from well above $7 \mathrm{TWh}$ to $2.5 \mathrm{TWh}$. One reason is that a large amount of balancing is now done (or avoided) through international cooperation among TSOs, such as imbalance netting. If those measures are accounted for, 4 TWh of balancing energy was used in 2017 still a sizable reduction, of $45 \%$ (Fig. 2). 


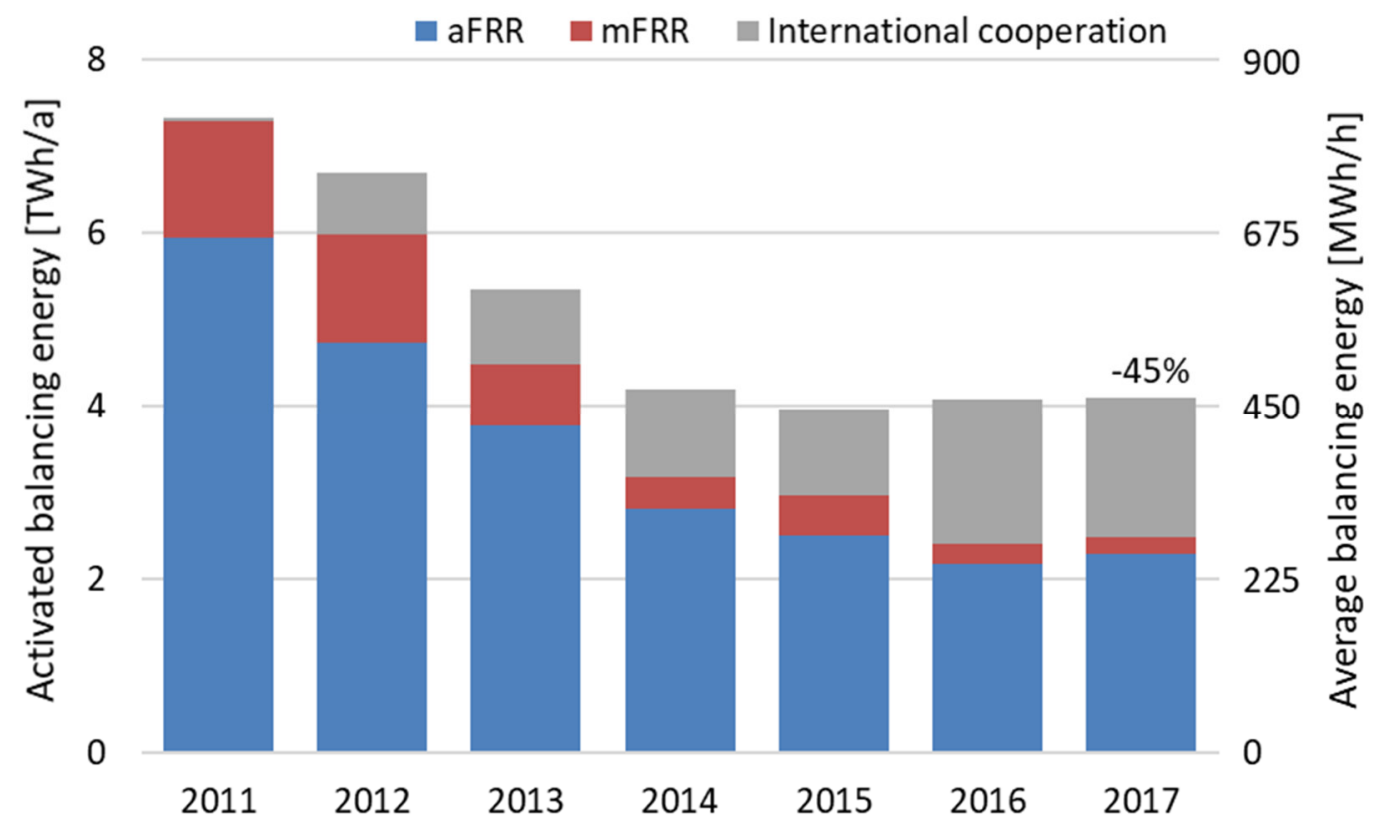

Fig. 2. Reserves activated by TSOs. In 2011, the activated balancing energy was 7.3 TWh/a (left axis), corresponding to $1.2 \%$ of the gross electricity consumption in Germany [35]. On average, $840 \mathrm{MWh} / \mathrm{h}$ capacity was activated (right axis). This dropped by $45 \%$ by 2017 . Beyond this, international imbalance netting reduced reserve activation by another $40 \%$.

For reserve sizing and system stability, it is not average activation that matters, but extreme situations. This is how the tails of the distribution developed: German TSOs publish situations with an activation of at least $80 \%$ of the available aFRR and mFRR [36]. There were 168 quarter-hours exceeding this threshold in 2012 (Table 1), almost all of them during Christmas Eve. This was due to a lack of active portfolio management by some market participants, so even high portfolio imbalances remained unnoticed. In stark contrast, there was only one such quarter-hour in the years 2014 and 2015 and there has been no such event since then despite the reduction in reserve size that was documented above.

Table 1. Number of quarter-hours with an activation of at least $80 \%$ of the balancing reserve.

\begin{tabular}{lc}
\hline Year & Activation \\
\hline $2011^{*}$ & 198 \\
2012 & 168 \\
2013 & 33 \\
2014 & 1 \\
2015 & 1 \\
2016 & 0 \\
2017 & 0 \\
\hline *The number for 2011 is an approximation based \\
on the actual data of the second half of that year.
\end{tabular}

The results in Table 1 indicate that the full FRR capacity has not been exhausted in recent years, and TSOs could have reduced the procured balancing reserve even more. This is 
investigated with an own calculation estimating the reserve requirement ex post. It is based on the same quarter-hourly reserve activation data, conservatively assuming imbalance netting to be unavailable. The TSO reliability target of 99.975\% [37] translates to slightly less than 1 quarter-hour per quarter of the year. This leads to reporting the most extreme observations for positive and negative activations for each quarter. Fig. 3 compares the reserves procured by TSOs with the ex-post calculation. In the years 2011 through 2013 the two measures match quite well, but there were actually several quarters where TSOs did not meet the reliability target. In sharp contrast, there is a significant over-procurement since 2014. In 2017, TSOs could reduce reserves by another 35\% without compromising their reliability target. In other words, the decrease in true balancing reserve requirement - holding the reliability level constant - is even more pronounced than the observed decline in procured reserve suggests.

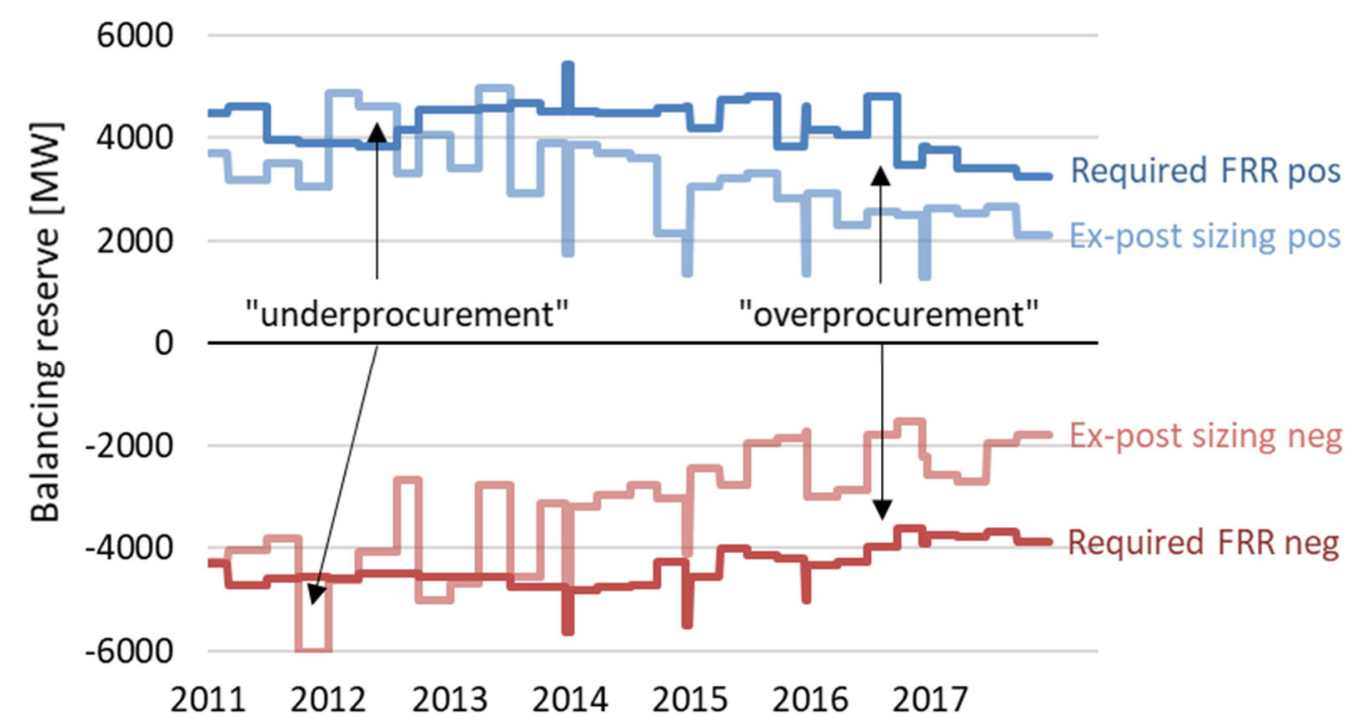

Fig. 3. Reserve procurement vs. ex-post sized reserves.

Hirth and Ziegenhagen [9] dubbed the decline of balancing reserves despite an increase in renewable energy the "German Balancing Paradox". Not only has this section confirmed this development, but the paradox seems now starker than ever: during a time when renewable energy grew by $110 \%$, balancing reserves probably could have been reduced by $50 \%$ and the use of these reserves by 55\%. Fig. 4 puts the main findings in context. 


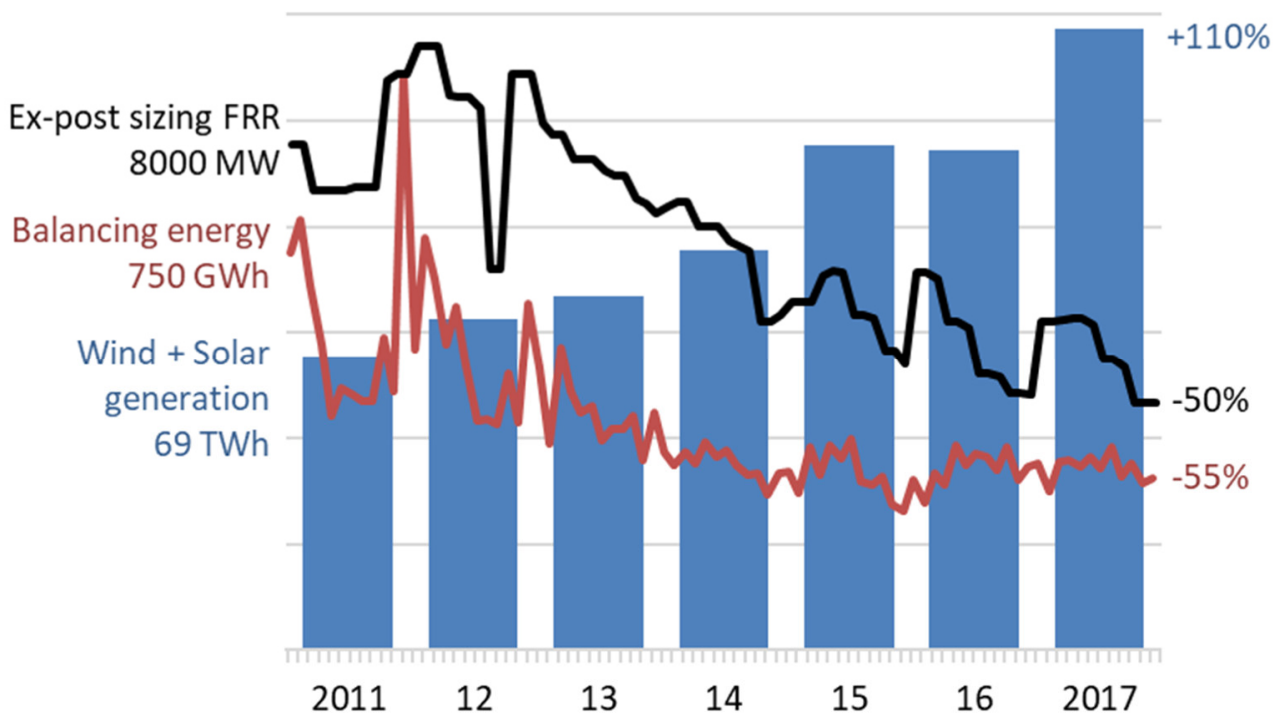

Fig. 4. Renewable energy and balancing needs.

\section{Data and Market Development}

The objective of this study is to assess the impact of intraday trading on the developments presented in section 2.2. The analyses are based on German data from 2012 to 2017, covering about 210,000 observations in quarter-hourly resolution. Data on the system balance, wind and solar generation, load and forecasts stem from TSOs and the European Network of Transmission System Operators for Electricity (ENTSO-E). Additionally, the study considers an extensive dataset containing every individual trade settled at EPEX SPOT. Table A1 in the Appendix reports on data sources. Providing a basis for the upcoming analyses, this section discusses two major intraday market trends of recent years: the extensive use of quarterhourly trading products and the implementation of more 24/7 trading.

\subsection{QUARTER-HOURLY TRADING}

EPEX SPOT launched quarter-hourly trading products on the continuous German intraday market in December 2011 and the quarter-hourly intraday auction in December 2014. The yearly trading volume increased by more than 6 times during this period (Fig. 5). The growth indicates a lack of quarter-hourly portfolio management before the market launch (because there was no suitable market). The consequences have been regular balancing reserve activations in 2012. The average system balance for that year shows clear deterministic patterns being most critical during steep load and solar ramps in the morning and evening [17,22]. They decreased in 2014 and virtually disappeared by 2017 (Fig. 6). There is a similar development of the utility frequency, as Weißbach et al. [38] show. 


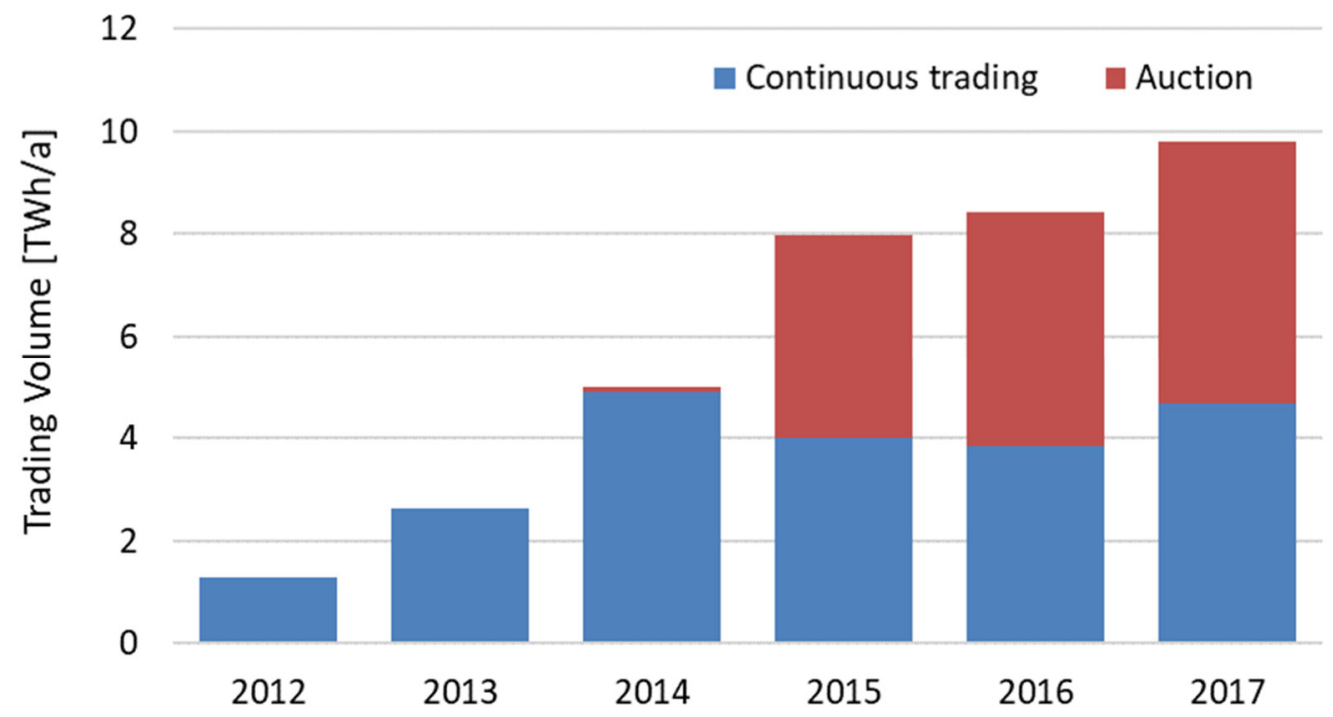

Fig. 5. Yearly trading volume on the intraday quarter-hourly auction and the continuous intraday trading of quarter-hourly products.

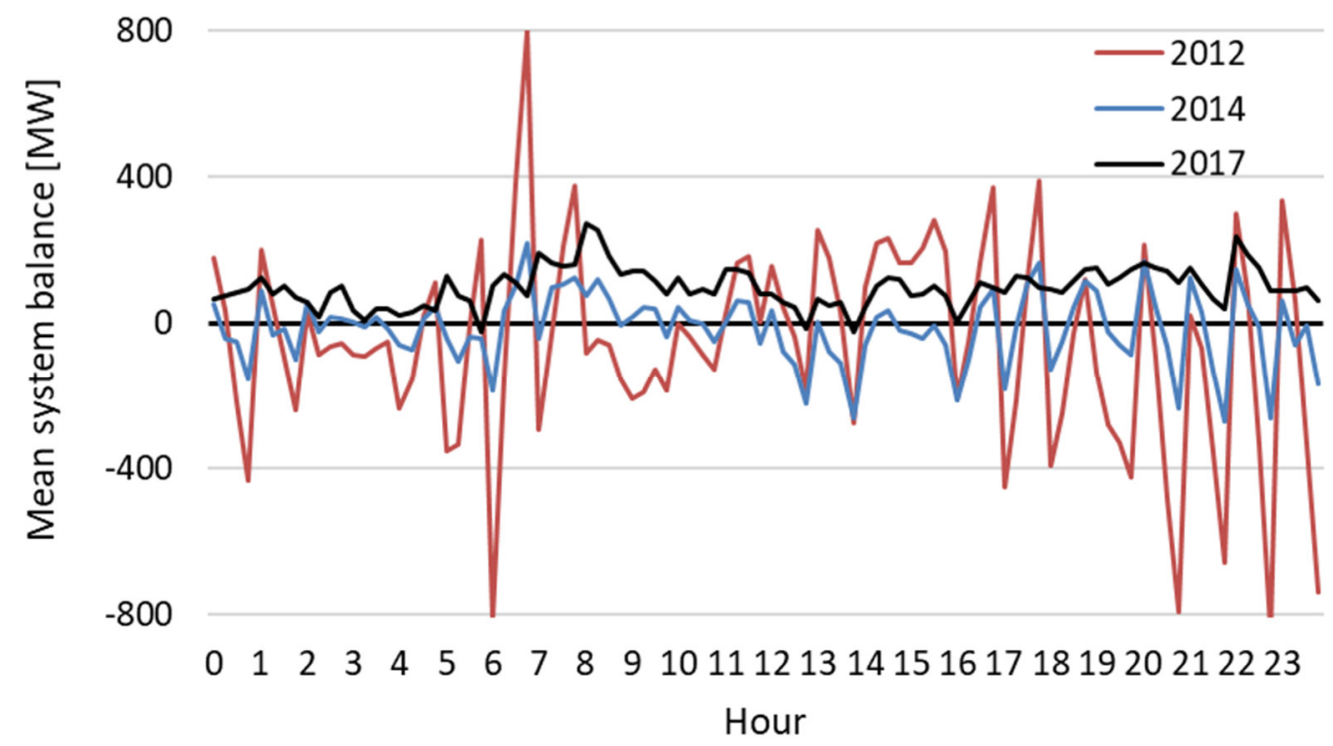

Fig. 6. Average system balance per quarter-hour for 2012, 2014 and 2017.

\subsection{4/7 TRADING}

In 2013, the Federal Network Agency charged that aggregators of non-dispatchable renewable generation units made too little effort on weekends, holidays and during the night in terms of active portfolio management until a short time before delivery [39]. The empirical analysis in this section studies whether the situation has changed following this warning. 
There are multiple indicators for liquidity and trading activity [40]. A simple method is to look at the trading volumes with a focus on comparing developments for peak and off-peak products. ${ }^{1}$ The overall trading volume on the hourly intraday market almost tripled between 2012 and 2017. The growth rate for off-peak products was 35 percentage points higher than that for peak products (Table 2). It shows a stronger focus on portfolio management during the night and on non-working days.

Table 2. Average hourly trading volume divided into peak and off-peak products. The trading volume grew significantly faster for off-peak products.

\begin{tabular}{lccc}
\hline & $\begin{array}{c}\text { Trading volume 2012 } \\
\text { (MWh) }\end{array}$ & $\begin{array}{c}\text { Trading volume 2017 } \\
\text { (MWh) }\end{array}$ & Growth rate (\%) \\
\hline Off-peak & 1177 & 3552 & 202 \\
Peak & 1968 & 5267 & 167 \\
\hline
\end{tabular}

The execution time of trades is another valuable indicator for analyzing the trading activity in a continuous market. An appropriate indicator is the time difference between the execution time of the single transactions and the gate closure time for the associated trading product to achieve a comparability between the different trading products. A lack of $24 / 7$ portfolio management means the majority of trading for night and weekend hours is done with a large time difference to delivery. This is critical for wind and solar portfolios as forecast accuracy improves with less time to delivery $[41,42]$.

Fig. 7 shows the median execution time before gate closure for the hourly intraday products of 2012 and 2017. The image confirms that in 2012, a host of market participants did not act $24 / 7$ on the continuous intraday market. The median is continuously growing for the trading products between midnight and 6 am and between 8 and 11 pm$^{2}$ - meaning with higher time lag to the regular office hours. ${ }^{3}$ There is a clear drop in the median execution time for products between 6 and 9 am. As the lead time was 45 min before delivery in 2012, there is a strong indication that many market players started active trading at around 7:30 am.

The course of the median execution time for hourly products in 2017 shows a behavioral change among market participants. There is a significant reduction of the median for nonoffice hours such that the numbers in the morning hours are similar to those of the afternoon

\footnotetext{
${ }^{1}$ Off-peak time is between 8 pm and 8 am on working days and during the whole of non-working days.

${ }^{2}$ The indicated time refers to the beginning of the hour. Thus, the trading product for delivery from 7 to 8 am is represented by 7 am.

${ }^{3}$ There is a jump between $11 \mathrm{pm}$ and midnight, because midnight is the beginning of the day and 11 pm its end. Trading for midnight is possible between $3 \mathrm{pm}$ and 11:30 pm the day before ( $8.5 \mathrm{~h}$ ), and for $11 \mathrm{pm}$ between $3 \mathrm{pm}$ the day before and 10:30 pm same day (31.5 h).
} 
hours. The time lag to gate closure is still the highest for the late evening hours, but the slope is smaller than in 2012.

One reason why the median execution time is still higher in the evening is the updating of the important global weather model of the European Centre for Medium-Range Weather Forecasts (ECMWF) between 6:00 and 7:00 in the morning and evening [43]. These data are the basis for renewable production forecasts [44], and updates provide significantly higher accuracy. Consequently, it is appropriate to make a first adaption of portfolio positions for the afternoon and evening hours based on the updated morning forecast.

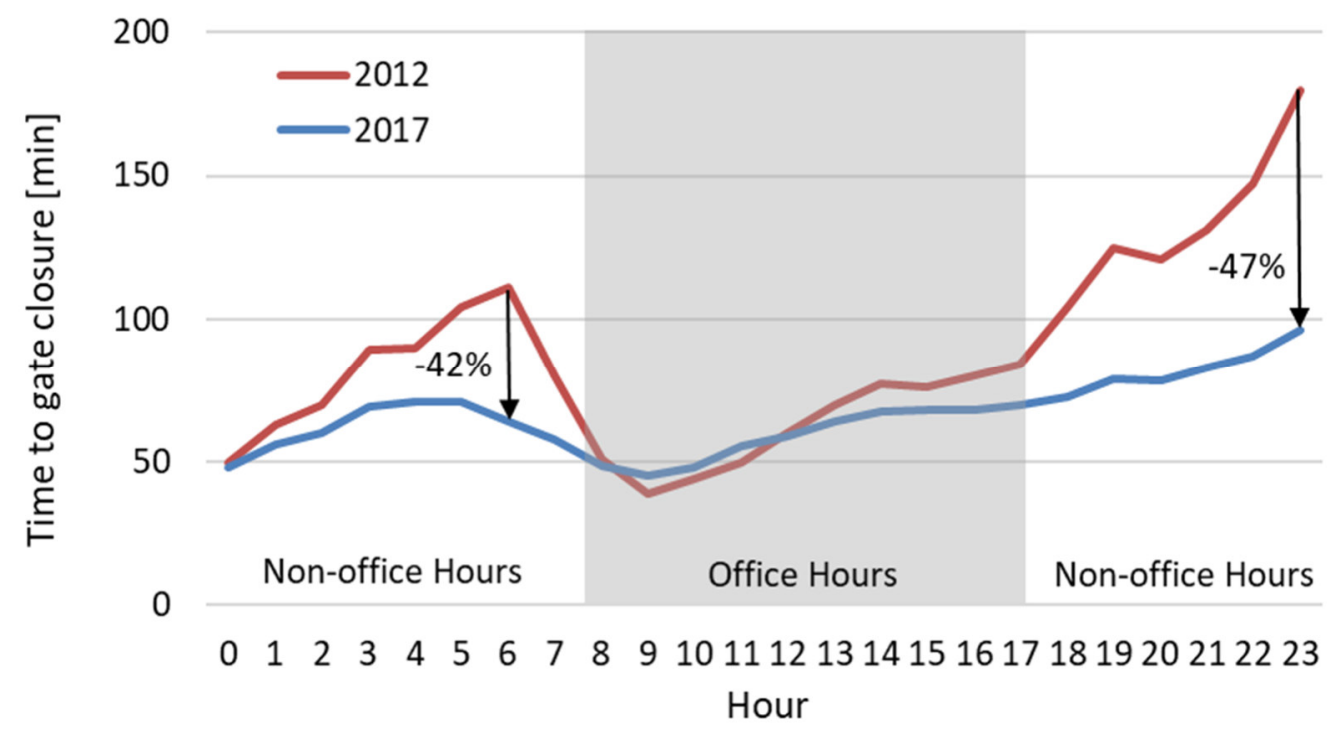

Fig. 7. Median execution time for 2012 and 2017.

\section{Methodology}

Analyzing the different effects of intraday trading on the system balance requires a more detailed definition of this term and its components up front. The quarter-hourly system balance $(Q S B)$ consists of the average hourly system balance $(H S B)$ and a within-hour deviation for each quarter-hour ( $\mathrm{Dev}$ ). The three variables are reported in power terms (MW) rather than energy terms (MWh).

$$
\begin{gathered}
H S B_{h}=\frac{1}{4} \sum_{q h=1}^{4} Q S B_{q h, h} \\
Q S B_{q h, h}=H S B_{h}+D e v_{q h, h}
\end{gathered}
$$

$h$ is the hour of the year $(1,2, \ldots, 8760)$ and $q h$ represents the quarter-hours of each hour $(1,2,3,4)$. 
HSB can be divided into three components: stochastic imbalances (Stochastic), such as power plant outages and forecast errors of solar and wind production or load; deterministic imbalances (Deterministic) that stem from coarse portfolio management, e.g. if market actors trade only peak/off-peak blocks rather than hourly products; and strategic imbalances (Strategic) to benefit from a bias of the imbalance price spread (see section 5.3).

$$
H S B_{h}=\text { Stochastic }_{h}+\text { Deterministic }_{h}+\text { Strategic }_{h}
$$

Similarly, $D e v_{q h, h}$ can be divided into the same three constituents: stochastic imbalances due to inaccurately predicted gradients, deterministic imbalances that stem from parties trading only hourly (but no quarter-hourly) products, and strategic imbalances that portfolio managers take consciously based on a forecasted imbalance price spread.

$$
\text { Dev }_{q h, h}=\text { Stochastic }_{q h, h}+\text { Deterministic }_{q h, h}+\text { Strategic }_{q h, h}
$$

Deterministic imbalances represent long-term predictable gradients. Those appear mostly for solar and load gradients that have a predictable diurnal pattern. Hence, they can be calculated as the deviation for every quarter-hour of a day $[q d(1,2, \ldots, 96)]$, averaged over all days of a year. It is not possible to analyze the schedules of individual parties with public data. So, the observed deterministic imbalances are net positions in the sense that they include strategic imbalances that counter deterministic patterns:

$$
\widehat{\operatorname{DetI}}_{q d}=\frac{1}{D} \sum_{d=1}^{D} \operatorname{Dev} v_{q d, d}
$$

with $q d=1,2, \ldots, 96$ denoting the quarter-hours of each day and $d=1,2,3, \ldots, 365$ representing the days of the year. To account for differences in diurnal solar and load patterns between winter and summer as well as working days and non-working days, Equation (5) is calculated separately for the quarters of the year and for working/non-working days.

These definitions are the basis for the explanation of the methods applied to address the research questions presented in section 1.

A multiple linear regression model assesses the relation of quarter-hourly intraday trading and the system balance (question 1). It considers pooled quarter-hourly data. The dependent variable is $D e v$, the deviation of the quarter-hourly system balance from the mean of that hour. Besides the trading volume, the model includes as control variables the deviation of wind, solar and load from their respective hourly means as exemplary illustrated for solar generation in Fig. 8. The deviations are defined as absolute numbers, because the trading volume is always positive as well. The model also includes dummies for the quarter-hours of a day $(Q d)$ to cover other systematic influences. The parameters are estimated using ordinary least squares. The specification of the first model is:

$$
\operatorname{Dev}_{t}=\beta_{0}+\beta_{1} \cdot \operatorname{Dev}_{\text {Solar }, t}+\beta_{2} \cdot \operatorname{Dev}_{\text {Wind }, t}+\beta_{3} \cdot \operatorname{Dev}_{\text {Load }, t}
$$




$$
+\beta_{4} \cdot \text { Trading volume }_{t}+\sum_{i=1}^{95} \kappa_{i} \cdot Q d_{i, t}+\varepsilon_{t}
$$

A second model also includes interaction terms between trading volume and the three withinhour deviations and between $D e v_{\text {Solar }}$ and $D e v_{\text {Load }}$, as there is probably a relationship between these parameters.

$$
\begin{aligned}
& \operatorname{Dev}_{t}=\beta_{0}+\beta_{1} \cdot \operatorname{Dev}_{\text {Solar }, t}+\beta_{2} \cdot \operatorname{Dev}_{\text {Wind }, t}+\beta_{3} \cdot \operatorname{Dev}_{\text {Load }, t} \\
& +\beta_{4} \cdot \text { Trading volume }_{t}+\beta_{5} \cdot \text { Trading volume }_{t} \cdot \text { Dev }_{\text {Solar }, t}+\beta_{6} \\
& \cdot \text { Trading volume }_{t} \cdot \text { Dev }_{\text {Wind }, t}+\beta_{7} \cdot \text { Trading volume }_{t} \\
& \cdot \operatorname{Dev}_{\text {Load }, t}+\beta_{8} \cdot \text { Dev }_{\text {Solar }, t} \cdot \text { Dev }_{\text {Load }, t}+\sum_{i=1}^{95} \kappa_{i} \cdot Q d_{i, t}+\varepsilon_{t}
\end{aligned}
$$

These models examine whether there is a significant correlation between increasing quarterhourly intraday trading volumes and decreasing $\mathrm{Dev} .{ }^{4}$ The second step is to assess the impact of quarter-hourly intraday trading on the system balance by simulating the effect of reduced systematic within-hour imbalances from 2012 to 2017. This requires the calculation of a hypothetical system balance without the effect of quarter-hourly trading. It is defined as follows:

$$
\text { Hypothetical } S B_{q}^{2017}=S B_{q}^{2017}+\left(\text { Determinısitc } c_{q d}^{2012}-\text { Determinıstıc }_{q d}^{2017}\right)
$$

The deterministic imbalances are calculated with the actual numbers for both years, as described in Equation (5). This time series is compared to the time series of the actual system balance to evaluate the influence on the total activation volume of balancing energy and the occurrence of high activation peaks.

\footnotetext{
${ }^{4}$ Statistical tests show heteroskedasticity and autocorrelation of the residuals. Therefore, Newey-West estimators are applied for calculating robust standard errors and confidence intervals of the coefficients.
} 


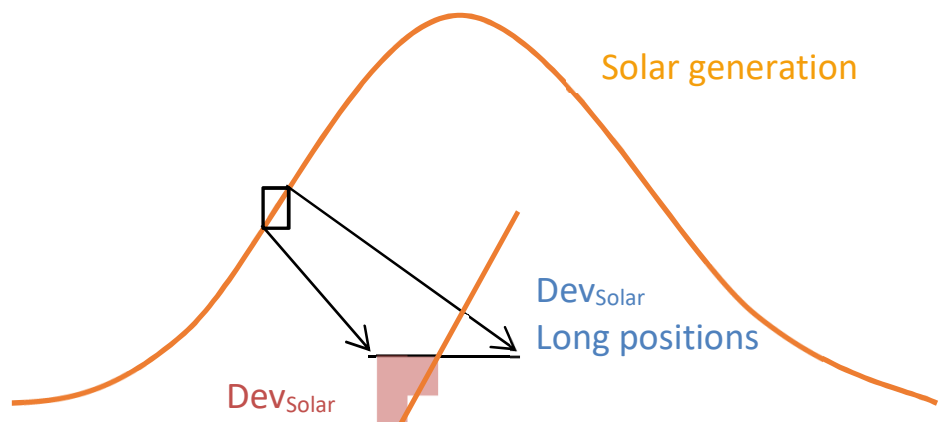

Short positions

Fig. 8. Within-hour deviations for solar generation.

Questions 2 and 3 are addressed with different empirical analyses. The impact of 24/7 trading on the system balance (question 2 ) is studied by analyzing boxplots of the absolute system balance for 2012 and 2017. An additional exploration focuses on the distribution of high absolute system balances for peak and off-peak hours, looking for systematic differences between 2012 and 2017. The limit is the $95^{\text {th }}$ percentile, calculated separately for the years 2012 and 2017. A further analysis will illustrate the relation to 24/7 trading. Active trading means a quick reaction to new portfolio information and public market data. Therefore, portfolio managers should be able to balance high imbalances faster. This can be tested by an examination of the average duration of consecutively high system balances. ${ }^{5}$ If the duration of large imbalances decreases more strongly for off-peak hours, this serves as an indicator for the impact of active portfolio management during non-office hours.

The last part of our analysis deals with the incentive of the imbalance price spread for market participants (question 3). The imbalance price spread is defined as imbalance price minus $\mathrm{ID}_{3}$ price. An economically efficient use of the intraday market leads to no profits from systematic short or long imbalance positions. This is studied with the empirical data including the associated effect on the system balance.

\section{Results}

This section presents the results of the analyses described in section 4. It begins by studying the impact of quarter-hourly intraday trading on the system balance (section 5.1), continues with an empirical analysis showing the effect of 24/7 trading (section 5.2) and ends with a discussion of biased balancing incentives and their implications for the system (section 5.3).

\footnotetext{
${ }^{5}$ Intervals of 1 or 2 quarter-hours are dropped for this calculation. In these cases, exceeding and falling below the limit cannot be caused by active intraday trading as its lead time was at least 30 min.
} 


\subsection{QUARTER-HOURLY TRADING}

Section 3.1 illustrates a parallel development of increasing quarter-hourly intraday trading volumes and declining systematic patterns of the system balance. Fig. 9 confirms the relationship between the two variables. It depicts at a weekly resolution the quarter-hourly intraday trading volumes and the average absolute within-hour deviation of the system balance $(D e v)$. Recalling Equation (4), Dev consists of a stochastic, a deterministic and a strategic part. The figure shows that the majority of the system stability improvement stems from a reduction of deterministic imbalances. They have been reduced by $80 \%$ over the considered period, and their share in Dev decreases from 76\% in 2012 to 26\% in 2017. This motivates the two-step approach of the upcoming analysis. The first step is to test the statistical significance of the influence of quarter-hourly trading and quantifying the effect. The second step is to estimate the impact on system balance reduction by focusing on the diminishing deterministic imbalances.

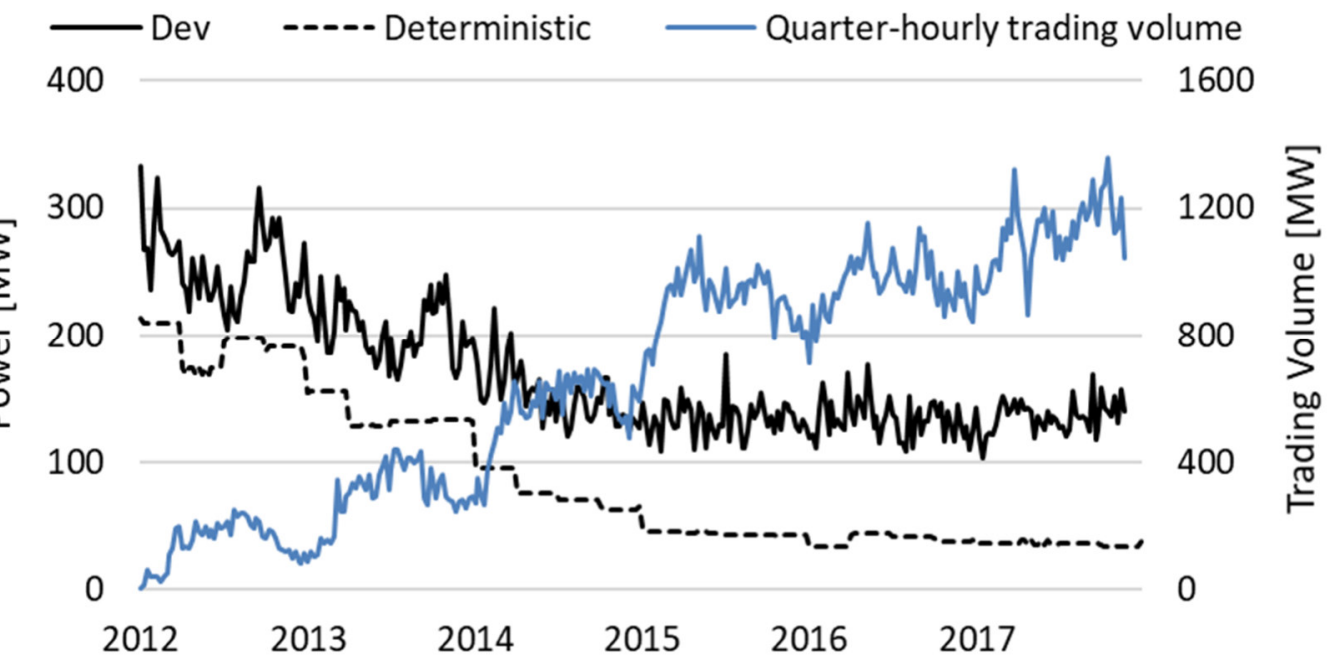

Fig. 9. Development of average absolute within-hour deviation (Dev), deterministic imbalance and average quarter-hourly intraday trading volume per week from 2012 to 2017. The seasonal pattern in trading volumes can be explained by the pattern of solar generation reducing the need to balance deterministic imbalances $[17,25,45]$. The methodology (Equation (5)) implies that deterministic imbalances remain quite constant within quarters of the year.

Table 3 summarizes the results of the regression models as described in Equations (6) and (7). The interdependency of trading volume and $D e v_{\text {Wind }}$ as a regressor is not significant at a $5 \%$ level. All other parameters are significant at a $0.1 \%$ level. The coefficient estimates show that an increase in absolute quarter-hourly deviations for photovoltaic, wind and electricity load leads, ceteris paribus, to higher quarter-hourly deviations of the system balance. This indicates that not all deviations are balanced on the intraday market. The coefficients for load and wind are higher than that for solar. A possible explanation for wind is that the gradients are more difficult to predict, because they are not systematic like the other two. The high coefficient for 
load suggests that quarter-hourly portfolio management was partly neglected by retailers during the considered period.

The coefficient for trading volume is -0.104 for the model without interdependencies, which means that the quarter-hourly deviation decreases by $0.104 \mathrm{MW}$ with every megawatt of trading volume. So, the results of the linear regression show the positive impact of quarterhourly intraday trading on the system balance by balancing within-hour deviations. The average trading volume is around $1200 \mathrm{MW}$ today. Based on the model estimation, this reduces the within-hour deviation for each quarter-hour by $120 \mathrm{MW}$.

Table 3. Results of the multiple linear regression models. The coefficients of the dummies are not presented, for reasons of simplicity.

\begin{tabular}{|c|c|c|c|c|c|c|}
\hline $\begin{array}{l}\text { Dependent variable: } \\
\text { Method: } \\
\text { No. of observations: }\end{array}$ & \multicolumn{6}{|c|}{$\begin{array}{l}\text { Absolute quarter-hourly deviation } \\
\text { Least squares } \\
210,432\end{array}$} \\
\hline & \multicolumn{3}{|c|}{$\begin{array}{c}\text { Model without } \\
\text { interdependencies }\end{array}$} & \multicolumn{3}{|c|}{$\begin{array}{c}\text { Model with } \\
\text { interdependencies }\end{array}$} \\
\hline Variable & Coefficient & & SE & Coefficient & & SE \\
\hline Intercept & 168.4 & $* * *$ & $(3.886)$ & 113.6 & $* * *$ & $(4.310)$ \\
\hline Trading volume & -0.104 & $* * *$ & $(0.003)$ & -0.054 & $* * *$ & $(0.003)$ \\
\hline Devsolar & 0.061 & $* * *$ & $(0.003)$ & 0.046 & $* * *$ & $(0.006)$ \\
\hline Dev $_{\text {Wind }}$ & 0.123 & $* * *$ & $(0.005)$ & 0.129 & $* * *$ & $(0.010)$ \\
\hline DevLoad & 0.088 & $* * *$ & $(0.003)$ & 0.161 & $* * *$ & $(0.004)$ \\
\hline Trading volume $*$ Devsolar & & & & $2.03 \cdot 10^{-5}$ & $* * *$ & $\left(2.76 \cdot 10^{-6}\right)$ \\
\hline Trading volume $*$ Dev $_{\text {Wind }}$ & & & & $-2.62 \cdot 10^{-6}$ & & $\left(6.63 \cdot 10^{-6}\right)$ \\
\hline Trading volume $*$ Dev Load & & & & $-7.20 \cdot 10^{-5}$ & $* * *$ & $\left(2.76 \cdot 10^{-6}\right)$ \\
\hline Devsolar $*$ Dev Load & & & & $-5.37 \cdot 10^{-5}$ & $* * *$ & $\left(4.41 \cdot 10^{-6}\right)$ \\
\hline R-squared & 0.240 & & & 0.274 & & \\
\hline Adjusted R-squared & 0.239 & & & 0.274 & & \\
\hline SE residuals & 148.5 & & & 145.1 & & \\
\hline F-statistic & 669.9 & $* * *$ & & 771.1 & $* * *$ & \\
\hline
\end{tabular}

SE: standard error. ${ }^{* * *}$ denotes that a test statistic is significant at the $0.1 \%$ level of significance using Newey-West estimators to calculate robust standard errors and confidence intervals in terms of heteroskedasticity and autocorrelation of the residuals.

The second part of the analysis addresses the influence of the decreasing within-hour deviations - especially by reducing deterministic imbalances - on the overall system balance. Deterministic imbalances influence the system balance in two ways. First, the total activation volume of balancing energy increases as predictable deviations are not balanced. Second, higher system balance peaks can occur, if the deterministic imbalances reinforce the stochastic and strategic imbalances. In this case, the TSOs must procure higher reserves. 
Both effects are analyzed by comparing the actual system balance for 2017 with a hypothetical system balance without the observed improvements (compare Equation (8)). ${ }^{6}$ Table 4 summarizes the results of the calculations. Reducing within-hour deviations alone has reduced the volume of balancing energy by $17 \%$ and the balancing reserve requirement by $7 \%$.

Table 4. Impact of reduced deterministic imbalances.

\begin{tabular}{lrrr}
\hline & $\begin{array}{c}\text { Actual system } \\
\text { balance 2017 }\end{array}$ & $\begin{array}{c}\text { Hypothetical system } \\
\text { balance 2017 }\end{array}$ & Difference \\
\hline $\begin{array}{l}\text { Total absolute system } \\
\text { balance (GWh) }\end{array}$ & 3131 & 3652 & $-16.6 \%$ \\
FRR ex-post sizing (MW) & 4703 & 5021 & $-6.8 \%$ \\
\hline
\end{tabular}

\subsection{4/7 TRADING}

The lack of 24/7 trading in 2012 could cause large imbalances specifically for wind and solar portfolios. Consequently, the absolute system balance could be higher during off-peak time. On the other hand, balancing group managers face less uncertainty of their portfolios during off-peak hours. The load is lower than during peak times and is well predictable due to moderate volatility $[46,47]$. Moreover, there is little solar production, as off-peak time includes mostly the night hours. The lower forecast uncertainty should lead to less imbalance.

Fig. 10 presents the final results of the opposed effects. The empirical data show that the absolute system balances are higher for peak than for off-peak hours. The median, lower and upper quartiles are all lower for the off-peak quarter-hours in 2012 and 2017, proving that there is mostly less demand for balancing reserve compared to peak quarter-hours. From 2012 to 2017, the relative deviation between the system balances for peak and off-peak hours is nearly constant for the lower quartile and the median. Little deviation occurs even when using the latest available forecasts, and more active trading has no effect on these situations. But the relative deviation increased for the upper quartile, from 3\% in 2012 to $12 \%$ in 2017. It seems that active portfolio management has an impact on high imbalances.

\footnotetext{
${ }^{6}$ The procurement of FRR for the hypothetical system balance is estimated by an application of the expost sizing method, as described in section 2.2 .
} 

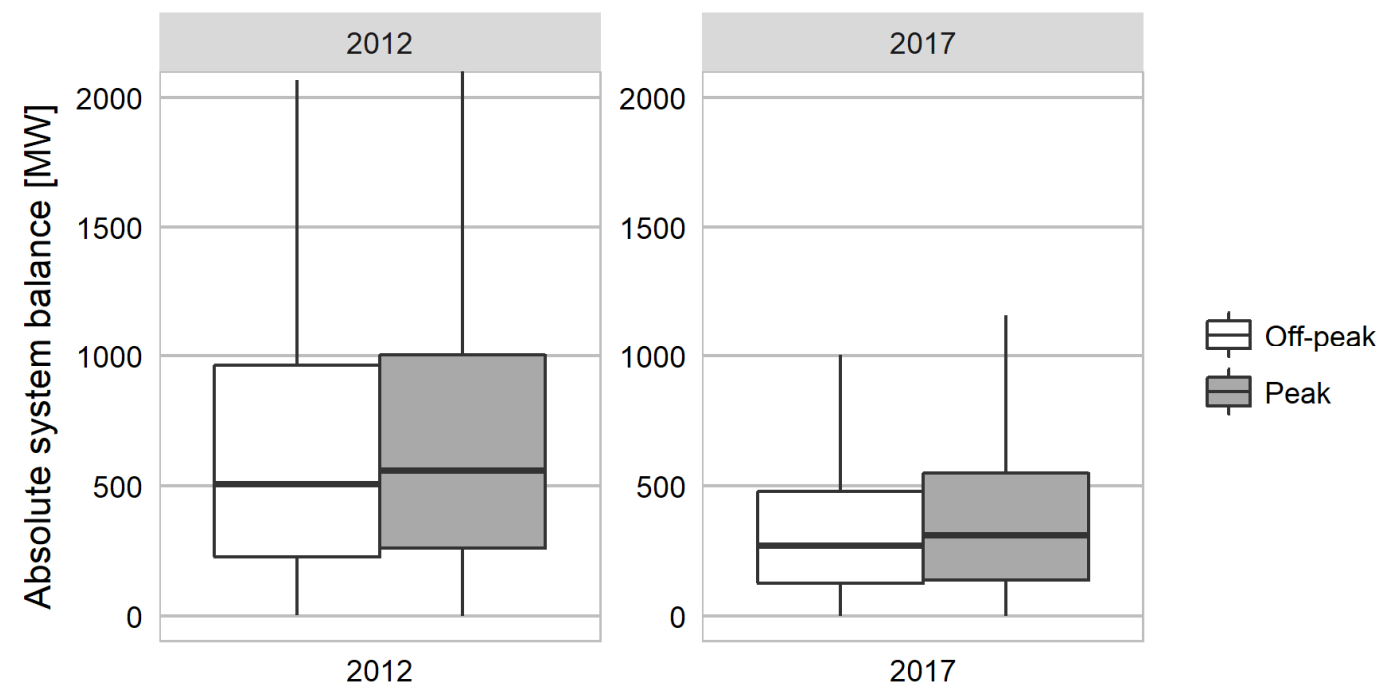

Fig. 10. Boxplots of the quarter-hourly absolute system balance for 2012 and 2017, distinguishing between peak and off-peak times.

Table 5 provides supporting evidence for this relation. It shows the distribution of quarterhours with the 5\% highest absolute system balances for 2012 and 2017. In 2012, 68\% of these situations occurred in off-peak hours. This share dropped to $54 \%$ in 2017. One reason for this might be 24/7 trading and a faster reaction to high imbalances, especially during non-office hours. It turns out that the average duration of high system balances dropped more strongly for the off-peak hours. In 2012, market participants reacted more slowly to high imbalances during off-peak hours than during peak hours, whereas they were faster in 2017.

Table 5. Quarter-hours with the 5\% highest system balances of a year.

2012 2017

\begin{tabular}{llcc} 
& & \multicolumn{2}{c}{ Number of observations } \\
& Peak & 566 & 812 \\
abs(system balance) $>\mathbf{P ( 0 . 9 5 )}$ & Off-peak & 1191 & 940 \\
& Share off-peak & $68 \%$ & $54 \%$ \\
\hline & & Number of quarter-hours \\
Mean duration & Peak & 9.29 & 5.86 \\
abs(system balance) $>\mathbf{P ( 0 . 9 5 )}$ & Off-peak & 11.80 & 5.13 \\
\hline
\end{tabular}

\subsection{BIASED BALANCING INCENTIVES}

While unexpected events will always make some reserve activation necessary, one would expect that on average the system as a whole is balanced. This is not, however, reflected in the studied data. During the years 2016-17, the German power system was systematically short of energy. On average, $144 \mathrm{MW}$ of upward balancing power must have been activated in those years (Fig. 11; Table 6). In that situation, one might expect systematic arbitrage opportunities to exist: it seems reasonable to assume that market actors could make a profit 
from systematically taking long positions, reducing the system imbalance (at least ex post). But the data show that virtually no profit was generated by taking systematically long or short positions in the balancing market. This is a clear indication of efficient markets.

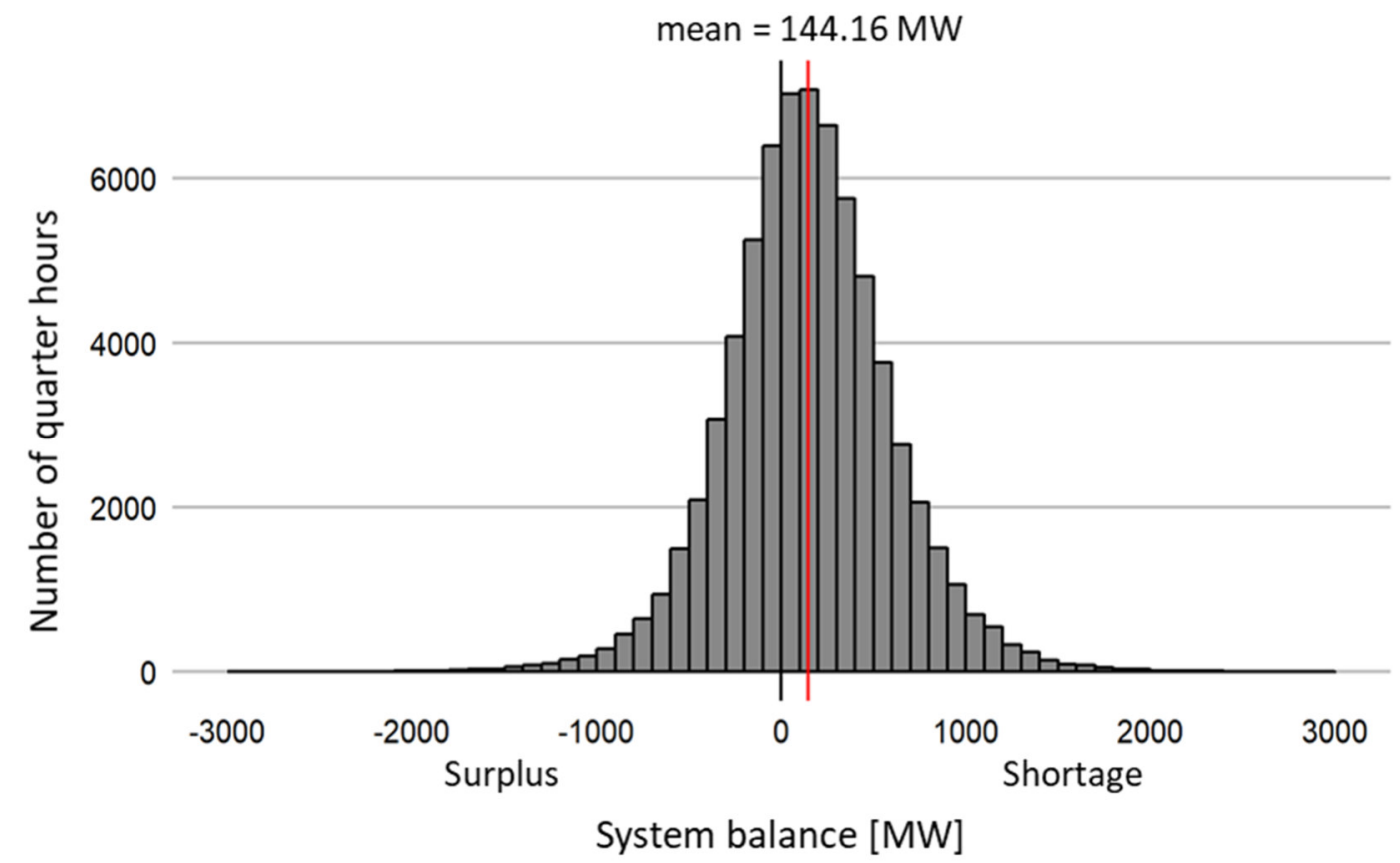

Fig. 11. Distribution of system balance in 2016-17. Note the shift toward positive imbalances.

Table 6. Descriptive statistics of the system balance in 2016-17.

\begin{tabular}{ll}
\hline Min & $-3007 \mathrm{MW}$ \\
First Quartile & $-125.8 \mathrm{MW}$ \\
Median & $135.9 \mathrm{MW}$ \\
Mean & $144.3 \mathrm{MW}$ \\
Third Quartile & $413.7 \mathrm{MW}$ \\
Max & $2930 \mathrm{MW}$ \\
Skewness & -0.02 \\
Kurtosis & 1.81 \\
\hline
\end{tabular}

These two observations seem to be inconsistent. They can be explained by the fact that absolute imbalance spreads tend to be larger if the system is long (Fig. 12). In other words, from a BRP's perspective, being short when the system is short involves a small penalty, but being long when the system is long involves a larger penalty. For example, during 2016-17 the imbalance price spread was around EUR 20 when the system was somewhat short of energy (up to $1000 \mathrm{MW}$ ). When the system was oversupplied with the same amount of energy, the imbalance price spread averaged EUR -37. This ratio also holds for higher absolute imbalances: surplus led to about twice the imbalance price spread that shortage did. It is therefore economically rational for market parties to err rather on the right side (to be short). Together with the asymmetry of the system balance, this leads to no profits from 
systematically long or short positions. This is an indication that the asymmetric imbalance price spreads cause the systematic shift of the system balance.

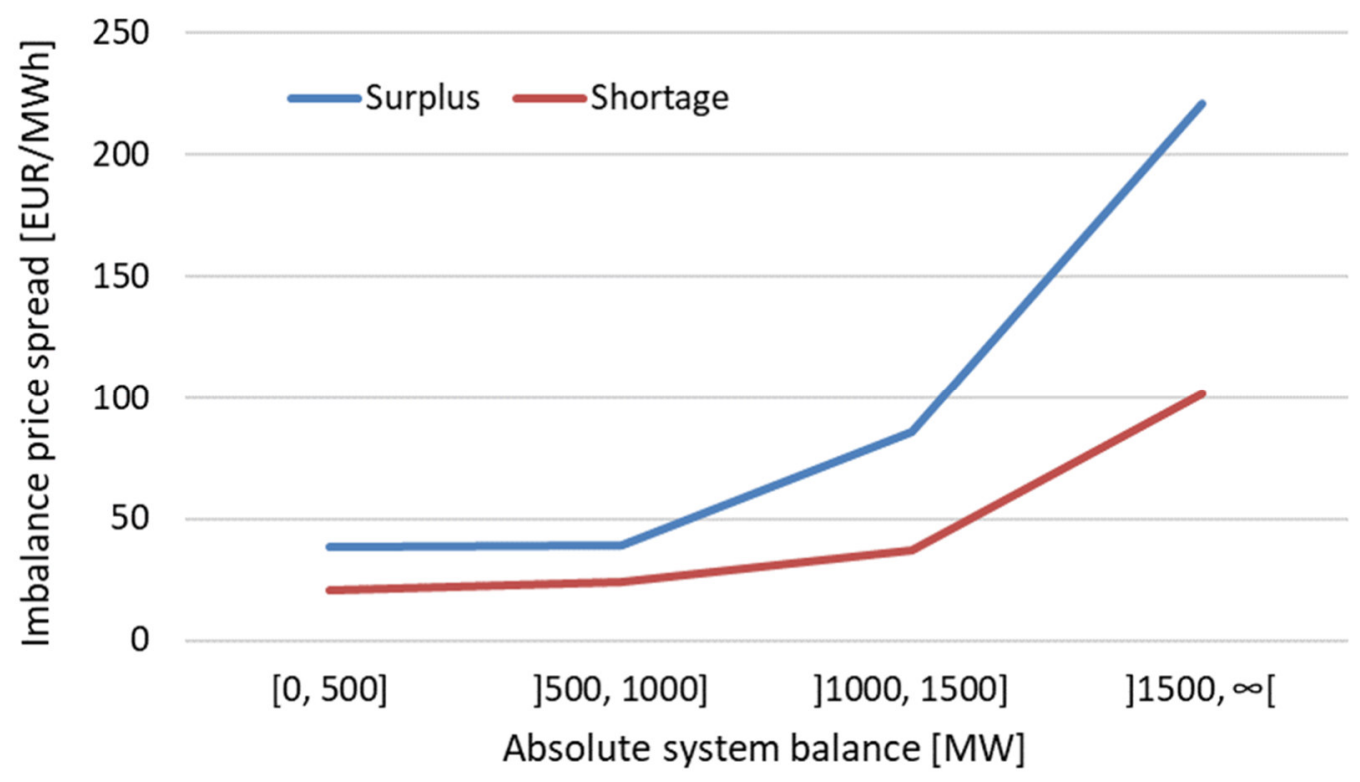

Fig. 12. Absolute imbalance price spread as a function of the absolute system balance for 2016-17.

Now contrast the status quo with the development over time. In most years before 2016, BRPs could make a significant profit by being systematically short (Fig. 13). The profit opportunity was most dramatic in 2011, when market actors who were persistently short by just $1 \mathrm{MW}$ would have earned EUR 18 per hour, or EUR 160,000 during that year. This finding is in line with Just and Weber [48] and Möller et al. [49], who report arbitrage opportunities for earlier years. After 2011, the profit opportunity was reduced over time. The improvement is an indicator of increasing market efficiency.

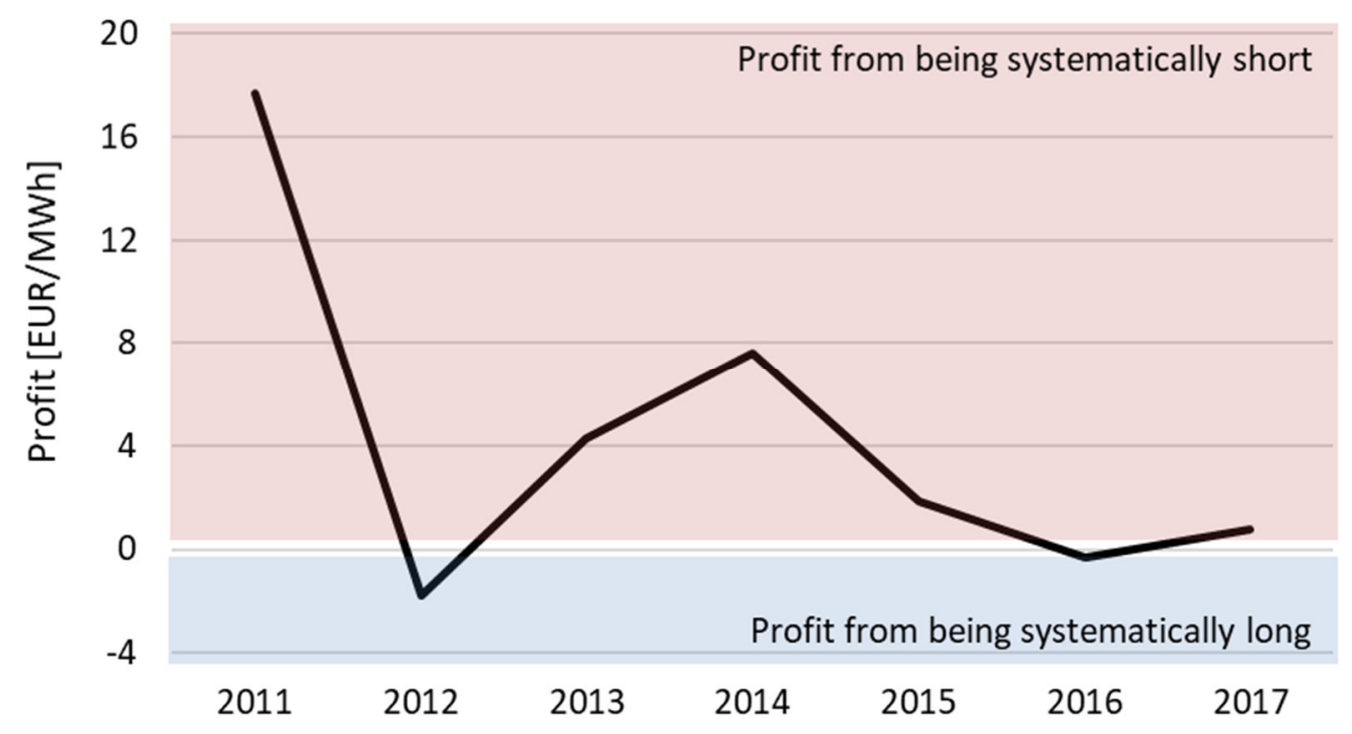

Fig. 13. Average annual imbalance price spread. 
Why was there a profit opportunity for being systematically short in 2011? The simple answer: because the power system was systematically oversupplied (Fig. 14). The incentives worked, market parties adjusted their positions and the systematic energy surplus disappeared, turning into a systematic shortage in the following years (Fig. 14). During that period, the market was finally efficient, in the sense that market parties have adjusted their positions so that no more systematic arbitrage opportunities exist between the intraday and the imbalance market (recall Fig. 13).

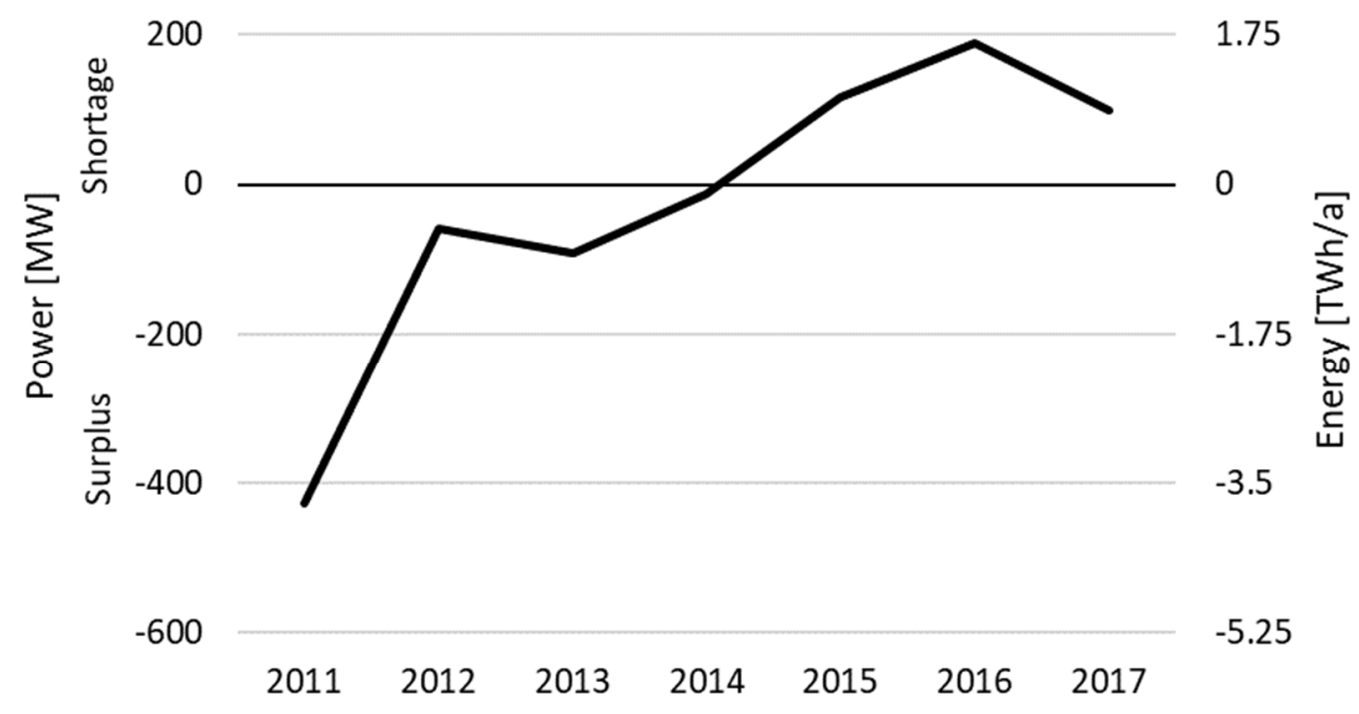

Fig. 14. The mean system balance went from a surplus to a shortage of energy. An average bias of $200 \mathrm{MW}$ (as in 2016) corresponds to 1.8 TWh annually.

It seems to be evident that asymmetric imbalance price spreads cause the asymmetry of the system balance, as illustrated in Fig. 11. Forecast errors are potentially another reason for that systematic shift. In contrast to forecast errors of load and renewable energy, unplanned outages are a biased source of imbalances in the sense that they can only lead to a shortage of energy, not to a surplus. However, a systematic change in the distribution of outages of power plants, loads or interconnectors seems unlikely.

Most market actors and TSOs rely on a small number of providers of forecasts for renewable energy generation. Those, in turn, build on even fewer weather models as primary data sources. A systematic shift in bias of wind and solar forecasts, as stated by some publications $[50,51]$, is a possible explanation. However, the data published by TSOs seems to falsify this hypothesis. In fact, during all the years 2012-16, German TSOs systematically overestimated production, a remarkable observation in itself (Fig. 15). The size of the systematic error increased in 2012-15, so that the system was pushed into a shortage of energy, which is consistent with the development of the system balance, and even the orders of magnitude match (a 200-MW increase in system balance; a 400-MW increase in forecast error). However, the hypothesis is less convincing in 2016-17. In 2016, the systematic forecast error was reduced by half, but the average system balance nearly doubled. In 2017, the average forecast error slumped by nearly $500 \mathrm{MW}$ while the system balance also declined, but by only $100 \mathrm{MW}$. 


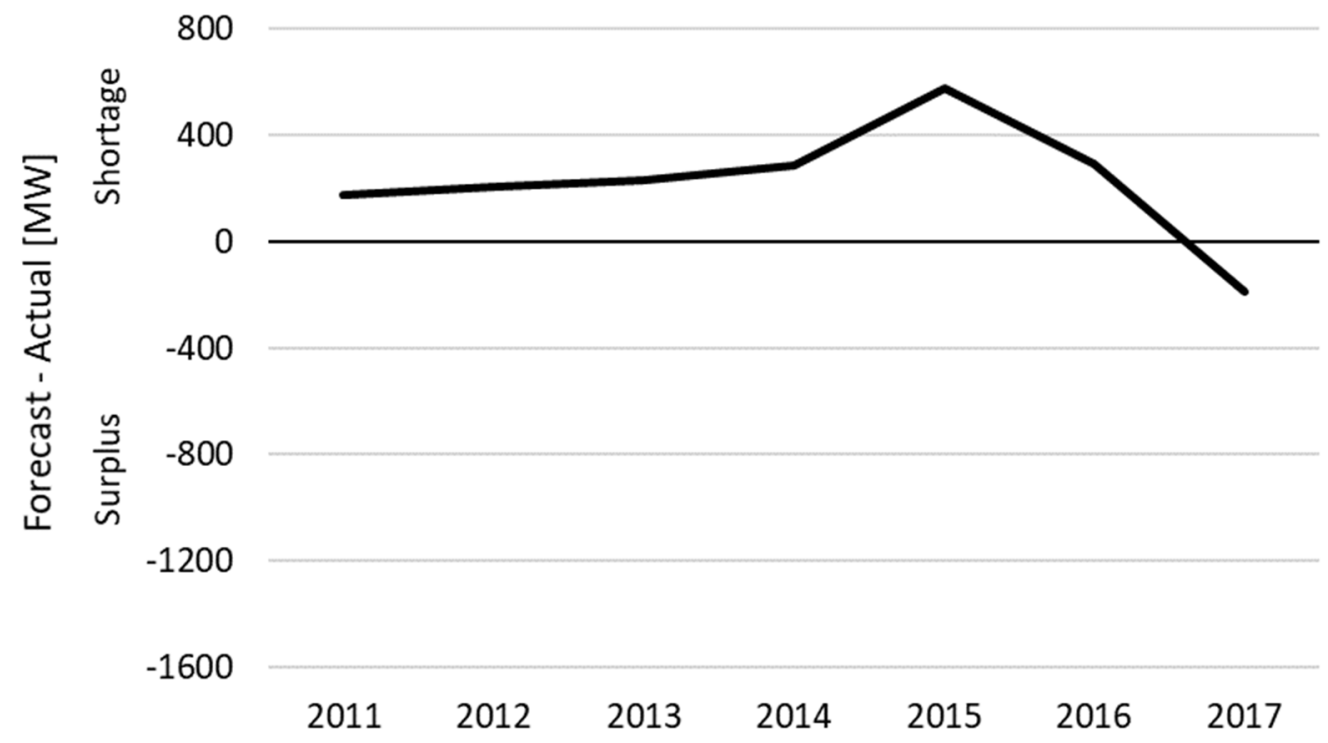

Fig. 15. TSO forecast errors of wind and solar energy (day-ahead forecast minus extrapolation of actual generation).

Chaves-Ávila et al. [52] and van der Veen et al. [53] emphasize that imbalance prices are an important motivation for active portfolio management. Given the collective evidence, incentives are the most plausible drivers behind this development. Significant arbitrage opportunities in 2011 led market actors to reduce systematic long positions. BRP behavior has been quite efficient since 2015 with respect to systematic deviations: they cannot make a systematic profit anymore. But this implies a systematic shortage of energy of 100-200 MW because of the asymmetric imbalance price spreads.

If system operators and regulators would like to see a systematically unbalanced system (zero average system balance), they should consider the incentives that market parties face. With symmetric spreads, the median system balance should quickly return to zero.

\section{Conclusions}

This paper finds further and robust evidence for the "German Balancing Paradox": during the years 2011-17, Germany's wind and solar generation more than doubled. At the same time, the use of balancing reserves decreased by $55 \%$, and reserves could have been reduced by $50 \%$ based on the presented analyses (in fact, TSOs reduced reserves by a mere 20\%). These findings confirm and extend previous estimates $[9,13]$. This is an indication that variable renewable energy can be integrated into power systems in large volumes at low cost - if processes, policies and markets are designed well and continually improved.

During that time, portfolio management at the 15-min scale (rather than over full hours) became increasingly common, as indicated by the sharp increase in quarter-hourly trading. 
This helped significantly to reduce imbalances, in particular predictable imbalances stemming from diurnal patterns in solar generation and electricity consumption. These "deterministic imbalances" were reduced by $80 \%$. To understand the relevance, consider the following thought experiment: if these improvements had not been realized between 2012 and 2017, balancing reserves would have been $7 \%$ larger and activation volumes would have been $17 \%$ larger. This is further supported by econometric evidence, as higher trading volumes reduce within-hour deviations of the system balance.

Electricity trading around the clock has become more common, as well: trading volumes increased particularly during night time and weekends, and trading now takes place close to real time during these off-peak hours also. It enables a faster reaction to high portfolio imbalances, especially during non-office hours, leading to a reduction in the occurrence of high absolute system balances during off-peak time.

The paper also reports evidence for efficient markets when it comes to imbalance charges. The system balance is biased (140 MW average shortage in 2016 and 2017), which can be fully explained by optimizing market parties: the penalty paid when being long (with the system also being long) is twice as high than the penalty for being short (when the system is also short). Naturally, portfolio managers try to err on the right side. In past years, parties could make a profit from being consistently short. This arbitrage opportunity is gone - an indication of efficient and mature markets.

Taken to a higher level, the evidence presented in this paper allows us to conclude that "incentives work". If the incentives are right and proper market design is available, markets efficiently integrate quite highly volumes of wind and solar energy. This should give us the confidence to rely on market-based approaches to short-term electricity system operation. The evidence that arbitrage opportunities will be exploited and hence markets will be biased if incentives are biased, however, should serve as a reminder to design these market-based approaches carefully.

\section{Acknowledgements}

The authors thank Entelios $\mathrm{GmbH}$ for access to market data on successfully settled trades at EPEX SPOT. 


\section{References}

[1] IEA. Monthly Statistics [Internet]. c2018 [cited 2018 Nov 8]. Available from: https://www.iea.org/statistics/monthly/\# electricity.

[2] NREL. The Western Wind and Solar Integration Study Phase 2. Golden, CO: National Renewable Energy Laboratory; 2013.

[3] Holttinen H, Meibom P, Orths A, Lange B, O'Malley M, Tande JO, et al. Impacts of large amounts of wind power on design and operation of power systems, results of IEA collaboration. Wind Energ. 2011;14:179-92.

[4] Brouwer AS, van den Broek M, Seebregts A, Faaij A. Impacts of large-scale Intermittent Renewable Energy Sources on electricity systems, and how these can be modeled. Renewable and Sustainable Energy Reviews 2014;33:443-66.

[5] Morbee J, Driesen J, Vos K de, Belmans R. Impact of wind power on sizing and allocation of reserve requirements. IET Renewable Power Generation 2013;7:19.

[6] dena. Grid Study II. Integration of Renewable Energy Sources in the German Power Supply System from 2015 - 2020 with an Outlook to 2025 [Internet]. c2010 [cited 2018 Nov 6].

[7] Deutsches Zentrum für Luft- und Raumfahrt, Fraunhofer Institut für Windenergie und Energiesystemtechnik, Ingenieurbüro für neue Energien. Langfristszenarien und Strategien für den Ausbau der erneuerbaren Energien in Deutschland bei Berücksichtigung der Entwicklung in Europa und global [Internet]. c2012 [cited 2018 Nov 6]. Available from:

http://www.fvee.de/fileadmin/publikationen/Politische_Papiere_anderer/12.03 .29.BMU_Leitstudie2011/BMU_Leitstudie2011.pdf.

[8] Batalla-Bejerano J, Trujillo-Baute E. Impacts of intermittent renewable generation on electricity system costs. Energy Policy 2016;94:411-20.

[9] Hirth L, Ziegenhagen I. Balancing power and variable renewables: Three links. Renewable and Sustainable Energy Reviews 2015;50:1035-51.

[10] Chang W-Y. A Literature Review of Wind Forecasting Methods. JPEE 2014;02:161-68.

[11] Haupt SE, Kosović B, Jensen T, Lazo JK, Lee JA, Jiménez PA, et al. Building the Sun4Cast System: Improvements in Solar Power Forecasting. Bull. Amer. Meteor. Soc. 2018;99:121-36.

[12] Miller SD, Rogers MA, Haynes JM, Sengupta M, Heidinger AK. Short-term solar irradiance forecasting via satellite/model coupling. Solar Energy 2018;168:10217.

[13] Ocker F, Ehrhart K-M. The "German Paradox" in the balancing power markets. Renewable and Sustainable Energy Reviews 2017;67:892-98.

[14] Scharff R, Amelin M. Trading behaviour on the continuous intraday market Elbas. Energy Policy 2016;88:544-57.

[15] Gianfreda A, Visconti Parisio L, Pelagatti MM. The Impact of RES in the Italian Day-Ahead and Balancing Markets. The Energy Journal 2016;37.

[16] Frade P, Vieira-Costa J, Osório G, Santana J, Catalão J. Influence of Wind Power on Intraday Electricity Spot Market: A Comparative Study Based on Real Data. Energies 2018;11:2974. 
[17] Märkle-Huß J, Feuerriegel S, Neumann D. Contract durations in the electricity market: Causal impact of 15 min trading on the EPEX SPOT market. Energy Economics 2018;69:367-78.

[18] Pape C. The impact of intraday markets on the market value of flexibility Decomposing effects on profile and the imbalance costs. Energy Economics 2018;76:186-201.

[19] Pape C, Hagemann S, Weber C. Are fundamentals enough?: Explaining price variations in the German day-ahead and intraday power market. Energy Economics 2016;54:376-87.

[20] Selasinsky Av. The integration of renewable energy sources in continuous intraday markets for electricity. Dissertation; 2016.

[21] Ziel F. Modeling the impact of wind and solar power forecasting errors on intraday electricity prices. In: 14th International Conference on the European Energy Market (EEM): IEEE; 2017.

[22] Kiesel R, Paraschiv F. Econometric analysis of 15-minute intraday electricity prices. Energy Economics 2017;64:77-90.

[23] Gianfreda A, Parisio L, Pelagatti MM. A review of balancing costs in Italy before and after RES introduction. Renewable and Sustainable Energy Reviews 2018;91:549-63.

[24] Joos M, Staffell I. Short-term integration costs of variable renewable energy: Wind curtailment and balancing in Britain and Germany. Renewable and Sustainable Energy Reviews 2018;86:45-65.

[25] Remppis S, Gutekunst F, Weißbach T, Maurer M. Influence of 15-minute contracts on frequency deviations and on the demand for balancing energy. In: International ETG Congress: IEEE; 2015.

[26] ENTSO-E. Continental Europe Operation Handbook [Internet]. c2019 [cited 2019 Apr 26]. Available from: https://www.entsoe.eu/publications/systemoperations-reports/\#continental-europe-operation-handbook.

[27] ENTSO-E. Continental Europe Operation Handbook [Internet]. c2018 [cited 2018 Nov 8]. Available from: https://docstore.entsoe.eu/publications/systemoperations-reports/operation-handbook/Pages/default.aspx.

[28] Commission Regulation (EU) 2017/2195: Guideline on Electricity Balancing.

[29] Commission Regulation (EU) 2017/1485: Guideline on Electricity Transmission System Operation.

[30] EPEX SPOT SE. Exchange Council approves the introduction of 15-minute contracts on the Belgian and Dutch market: Trading until delivery to be launched on the German market on 14 June 2017 [Internet]. c12.06.2017 [updated 2017 Jun 12; cited 2019 Apr 11]. Available from: https://www.epexspot.com/document/37626/170612_EPEX\%20SPOT_Exchang e\%20Council.pdf.

[31] Bundesnetzagentur. Monitoringbericht 2018: Elektrizitätsmarkt -DSystemdienstleistungen [Internet]. c2018 [cited 2019 Mar 22]. Available from: https://www.bundesnetzagentur.de/DE/Sachgebiete/ElektrizitaetundGas/Unter nehmen_Institutionen/DatenaustauschundMonitoring/Monitoring/Monitoringb erichte.

[32] ENTSO-E. Survey on Ancillary Services Procurement, Balancing Market Design 2017 [Internet]. c2018 [cited 2018 Nov 6]. Available from: 
https://docstore.entsoe.eu/Documents/Publications/Market\%20Committee\%2 0publications/ENTSO-E_AS_survey_2017.pdf.

[33] BMWi. Zeitreihen zur Entwicklung der erneuerbaren Energien in Deutschland [Internet]. c2018 [cited 2018 Nov 6]. Available from: https://www.erneuerbareenergien.de/EE/Navigation/DE/Service/Erneuerbare_Energien_in_Zahlen/Zeitre ihen/zeitreihen.html.

[34] Glau M. Regelenergiemarkt zwischen Gestern und Morgen: Was kommt nach dem Mischpreisverfahren? Berlin; 2019.

[35] BMWi. Sixth “Energy Transition” Monitoring Report - Reporting Year 2016: The Energy of the Future [Internet]. c2018 [cited 2019 May 9]. Available from: https://www.bmwi.de/Redaktion/EN/Publikationen/Energie/sechstermonitoring-bericht-zur-energiewende-langfassung.html.

[36] 50Hertz Transmission GmbH, Amprion GmbH, TenneT TSO GmbH, TransnetBW GmbH. Daten zur Regelenergie [Internet]. c2018 [cited 2018 Nov 6]. Available from: https://www.regelleistung.net/ext/data/.

[37] Consentec GmbH. Verfahren zur dynamischen Bestimmung des Bedarfs für Sekundärregel- und Minutenreserve [Internet]. c2018 [updated 2018 Nov 6]. Available from: https://www.regelleistung.net/ext/tender/remark/news/345.

[38] Weißbach T, Remppis S, Lens H. Impact of Current Market Developments in Europe on Deterministic Grid Frequency Deviations and Frequency Restauration Reserve Demand. In: 2018 15th International Conference on the European Energy Market (EEM): IEEE; 2018.

[39] Bundesnetzagentur. Positionspapier zur Wahrnehmung der Pflichten nach § 4 Abs. 2 StromNZV und Ziffer 5.2. des Standardbilanzkreisvertrages durch die Bilanzkreisverantwortlichen [Internet]. c2013 [updated 2018 Apr 10]. Available from: https://www.bundesnetzagentur.de/DE/Service-

Funktionen/Beschlusskammern/1BK-Geschaeftszeichen-Datenbank/BK6GZ/2013/2013_0001bis0999/2013_100bis199/BK6-13-104/BK6-13104Positionspapier.html?nn=269902.

[40] Hagemann S, Weber C. An Empirical Analysis of Liquidity and Its Determinants in the German Intraday Market for Electricity. SSRN Journal 2013.

[41] Weber C. Adequate intraday market design to enable the integration of wind energy into the European power systems. Energy Policy 2010;38:3155-63.

[42] Zhang J, Hodge B-M, Florita A. Joint Probability Distribution and Correlation Analysis of Wind and Solar Power Forecast Errors in the Western Interconnection. J. Energy Eng. 2015;141:B4014008.

[43] ECMWF. Dissemination Schedule [Internet]. c2018 [cited 2018 Aug 6]. Available from: https://www.ecmwf.int/en/forecasts/documentation-and-support/datadelivery/dissemination-schedule.

[44] Sperati S, Alessandrini S, Delle Monache L. An application of the ECMWF Ensemble Prediction System for short-term solar power forecasting. Solar Energy 2016;133:437-50.

[45] Wolff G, Feuerriegel S. Short-term dynamics of day-ahead and intraday electricity prices. Int J of Energy Sector Man 2017;11:557-73.

[46] Bessec M, Fouquau J. Short-run electricity load forecasting with combinations of stationary wavelet transforms. European Journal of Operational Research 2018;264:149-64. 
[47] Clements AE, Hurn AS, Li Z. Forecasting day-ahead electricity load using a multiple equation time series approach. European Journal of Operational Research 2016;251:522-30.

[48] Just S, Weber C. Strategic behavior in the German balancing energy mechanism: Incentives, evidence, costs and solutions. J Regul Econ 2015;48:218-43.

[49] Möller C, Rachev ST, Fabozzi FJ. Balancing energy strategies in electricity portfolio management. Energy Economics 2011;33:2-11.

[50] Tang Y, Zhong J, Bollen M. Schedule of air-conditioning systems with thermal energy storage considering wind power forecast errors. International Journal of Electrical Power \& Energy Systems 2018;95:592-600.

[51] Lienert M. Leistungsvorhaltung auf Regelmärkten: Excel Add-in, Beschreibung und Anleitung; 2008. Available from: http://www.ewi.unikoeln.de/fileadmin/user_upload/Publikationen/Working_Paper/EWI_WP_0803_Leistungsvorhaltung-auf-Regelmaerkten.pdf.

[52] Chaves-Ávila JP, van der Veen RAC, Hakvoort RA. The interplay between imbalance pricing mechanisms and network congestions - Analysis of the German electricity market. Utilities Policy 2014;28:52-61.

[53] van der Veen RAC, Abbasy A, Hakvoort RA. Agent-based analysis of the impact of the imbalance pricing mechanism on market behavior in electricity balancing markets. Energy Economics 2012;34:874-81. 


\section{Appendix}

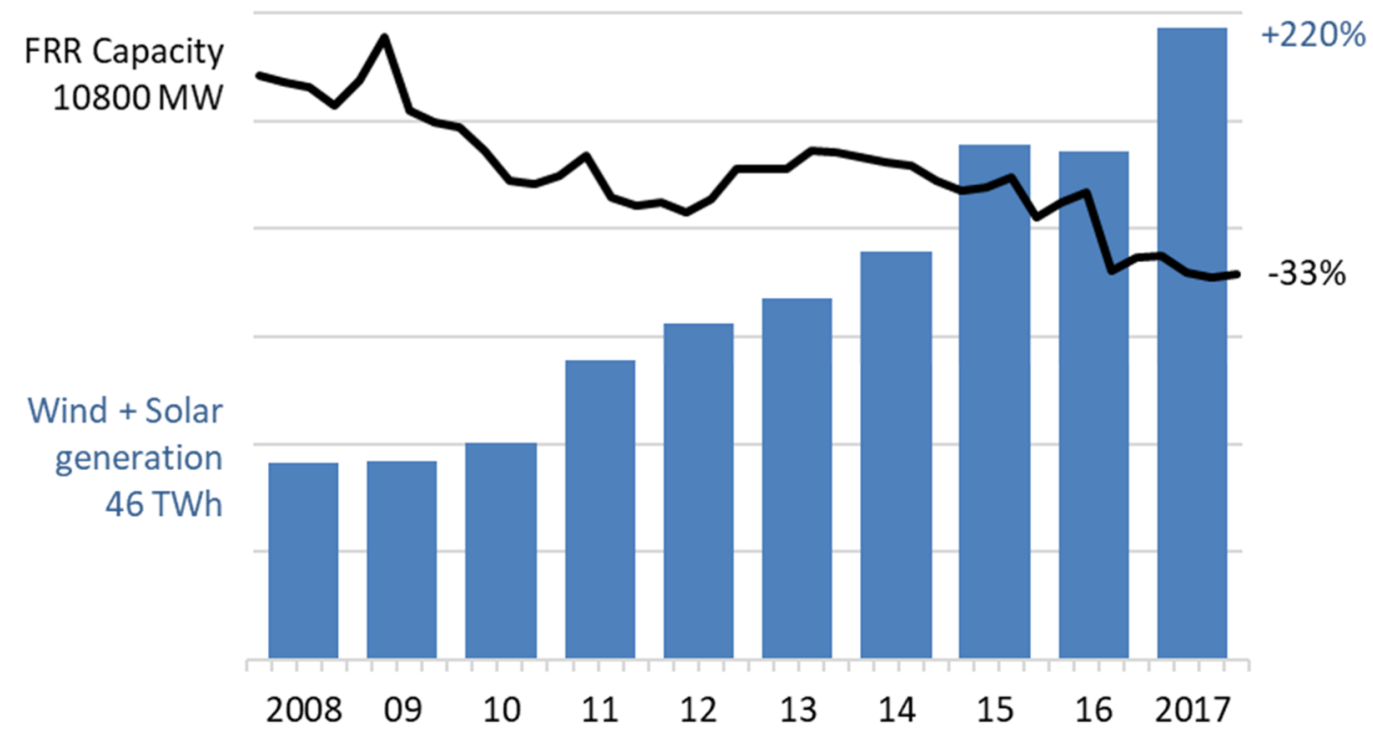

Fig. A1. Frequency restoration reserves procured by TSOs and generated energy from wind and solar plants from 2008 to 2017.

Table A1. Overview of data used and data sources.

\begin{tabular}{|c|c|}
\hline Data & Source \\
\hline System balance & $\begin{array}{l}\text { Common platform of German TSOs: } \\
\text { https://www.regelleistung.net/ext/data/ }\end{array}$ \\
\hline $\begin{array}{l}\text { Intraday trading volume per } \\
\text { quarter-hour }\end{array}$ & Entelios GmbH \\
\hline Intraday trading volume per hour & Entelios $\mathrm{GmbH}$ \\
\hline $\begin{array}{l}\text { Execution time of hourly intraday } \\
\text { trades }\end{array}$ & Entelios GmbH \\
\hline $\begin{array}{l}\text { Imbalance price spread: } \\
\text { Imbalance price - ID3 price }\end{array}$ & $\begin{array}{l}\text { Common platform of German TSOs: } \\
\text { https://www.regelleistung.net/ext/data/ } \\
\text { Entelios GmbH }\end{array}$ \\
\hline Actual wind and solar production & $\begin{array}{l}\text { Transmission system operators: } \\
\text { http://www.50Hertz.com, http://www.amprion.de, } \\
\text { http://www.transnetbw.de, http://www.tennettso.de }\end{array}$ \\
\hline Actual electricity load & $\begin{array}{l}\text { European Network of Transmission System Operators } \\
\text { (ENTSOE): https://transparency.entsoe.eu/ }\end{array}$ \\
\hline $\begin{array}{l}\text { Forecasts for wind and solar } \\
\text { production }\end{array}$ & $\begin{array}{l}\text { Transmission system operators: } \\
\text { http://www.50Hertz.com, http://www.amprion.de, } \\
\text { http://www.transnetbw.de, http://www.tennettso.de }\end{array}$ \\
\hline
\end{tabular}

